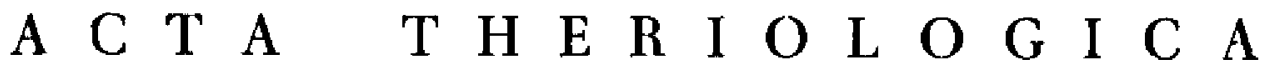 \\ VOL. $19,14: 191-234$. \\ BIAEOWIEŹA \\ September, 1974
}

\author{
Kyle R. B A R B E H E N N
}

\section{Estimating Density and Home Range Size with Removal Grids: the Rodents and Shrews of Guam}

[With 6 Tables 11 Figs.]

\begin{abstract}
Deriving valid estimates of density and home range size from removal grids requires that the observed responses of trapped populations fit a theoretical model and that sources of bias be examined and corrected when necessary. From assumptions concerning the relationships between home range radius ( $r)$, the probability of capture $(p)$, and the location of home range centers (HRC's) with reference to the grid squares, a model was developed to predict both the relative catch on each grid square and the expected rates of removal. The model was tested with empirical results for the shrews (Suncus murinus) and rats ( $R$. rattus and $R$. exulans) of Guam. Experimental variables included grids with different trap spacings $(d=15,30$, and $42 \mathrm{~m}$ ), either leaving traps in place or shifting them to mid-points after two days of removal trapping, and the duration of trapping (from 4 to 30 days).

The model predicted that the relative catch on the outer grid square $(\omega)$ would vary with $\tau$ and it is assumed that observed variation in the relative catch on $\omega$ was a function of $r$. The absence of an edge effect on the penultimate grid square suggested that these animals tend to be caught in traps nearest to their HRC's. In general, $\omega$ acted as a good filter for animals whose HRC's were assumed to be primarily outside the grid during short-term trapping. Invasion of the inner squares was induced by extended trapping. The model predicted a constant $p$ on the inner squares and this was generally observed where $d=15 \mathrm{~m}$. However, $p$ generally changed with time where $d=30$ and $42 \mathrm{~m}$. Experimental shifting of traps revealed that many animals were not exposed to traps where $d=30 \mathrm{~m}$ and the changing $p$ on grids with wide spacing was apparently caused by an expansion of $r$ by those animals not initially exposed to traps. The model assumed that $p$ would decrease with distance of the HRC from the grid, producing a concave rather than a linear catch curve, with the mean slope decreasing as $r$ increased. In fact, the initial $\hat{p}$ was highest on $\omega$ when $\hat{r}$ was largest and the catch on $\omega$ actually increased with time when $\stackrel{r}{r}$ was small. This was also interpreted as an expansion of $r$. If $r$ expands as trapping proceeds, an estimate of the initial $r$ can be obtained only on the first day of trapping by using $\mathrm{H}$ an s s o n's (1969) equation and modified assumptions. For Suncus and R. rattus, $\hat{\imath}$ varied from 7 to $30 \mathrm{~m}$; for $R$. exulans, from 4 to $20 \mathrm{~m}$ at the population level. The catch on the outer square could not be used reliably to estimate density under any circumstances because the area of effect changed with time.
\end{abstract}


Confidence limits for $\hat{N}$ were developed from Zippin's (1956, 1958) SE $(\hat{p})$ for individual samples. Consistency in $\hat{p}$ among the samples permitted a more precise estimate of $\bar{p}$ and substantial reduction in the confidence limits for small samples. The lower limit for $\hat{N}$ cannot be less than the total catch $(T)$ and, for most samples of shrews, the upper limit for $\hat{N}$ was $1.17 T$. Precision for the two rats and for $M u s$ was lower. Roughly 10 percent of the samples yielded statistically aberrant results that had to be treated subjectively. Such occassional results do not discredit the general value of the inner square method. However, homogeneity in the distribution of animals is essential for reliable estimates and, when a positive edge effect is not regularly observed on day-1, the assumption that all animals on the inner squares are exposed to traps must be tested. This is specially true when prebaiting leads to an artificially high estimate of $\hat{p}$. My conclusions should not be applied directly to small mammals whose activities are vertically stratified and to those that make extensive use of runways.

I. Introduction

1. Background

2. Standard methods: Terminology

II. A Model

1. Statics

2. Kinetics

III. An Example: Introduction

1. Area and methods

2. Analytical procedures

IV. Home range size and rate of captur

1. Distribution of catches on squares . . . . . . . . . . 202

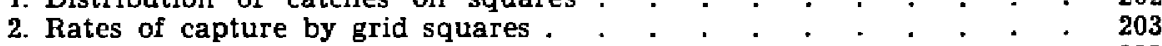

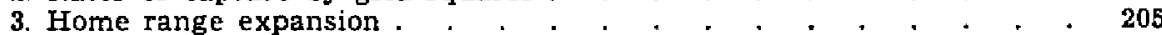

4. Effects of trap spacing . . . . . , . . . . . . . 206

5. The probability of encountering traps. . . . . . . . . 208

6. Mus and neophobia . . . . . . . . . . . . 209

v. Invasion . . . . . . . . . . . . . . . . . . . 212

VI. Estimating home range radius ( $($ )

1. Background procedures and problems . . . . . . . . . 216

2. A recommended procedure . . . . . . . . . . . , 217

3. Confirmation 219

4. Implications of the observations on range size . . . . . . . 221

VII. Estimating density . . . . . . . . . . . . . . . . . . . . 221

1. Variability . . . . . . . . . . . . . . . . . 222

2. Positive edge effect . . . . . . . . . . . . . . . . 222

3. Negative and zero edge effect . . . . . . . . , . . 226

VIII. Confidence limits and reliability . . . . . . . . . . . . . . 225

1. Goodness of fit . . . . . . . . . . . . . . . . . 226

2. Confidence limits for $\hat{N}$. . . . . . . . . . . . . 227

3. Consistency of $\hat{p}$. . . . . . . . . . . . . . . 227

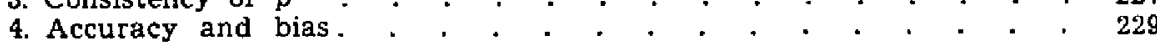

5. Sample size. . . . . . . . . . . . . . . . . 229

6. Supplementary proofs : . . . . . . . . . . . . . 230

IX Discussion . . . . . . . . . . . . . . . . , , 231

References . . . . . . . . . . . . . . . . . . 232

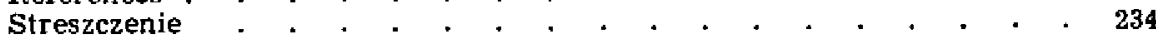




\section{INTRODUCTION}

\section{Background}

The search for a single, standard way to estimate the densities of small mammals has been hampered by excessive variability in observed patterns of capture: variability that often makes the results unreliable. Given a standard method of laying traps, such as the "Standard Minimum" ( $\mathrm{F}$ rodzinski, Pucek \& Ryszkowski, 1966) reasons for variability in trap response include the fact that the use of space varies both with the species and the situation. The purpose of this paper is to analyse and interpret the patterns of trap response for one particular set of species and conditions, to compare empirical observations with those expected from theoretical considerations, and to evaluate the reliability of estimating density and home range size with removal grids for one community of small mammals. Since a comprehensive review of field methods is in preparation elsewhere (Michael H. Smith, personal communication) I will generally confine discussion to topics of special relevance and familiarity.

The way an individual uses space influences its probability of encountering an array of traps set on the ground surface in a checkerboard grid. We are relatively ignorant of many important details concerning patterns of movement but some special cases can be identified and methods adjusted accordingly. Semi-fossorial and semi-arboreal patterns may be countered by stratifying traps appropriately (B a $\mathrm{r}$ be he $\mathrm{n} n, 1973$ ). Animals that travel primarily on narrow paths or runways, such as many microtines, may not be exposed to traps placed within the external boundaries of their home ranges and this generates difficult analytical and methodological problems ( $B$ a $r$ be $h$ e $n n, 1974$ ). While more extreme patterns may easily be seen, other patterns may be more subtle and go unrecognized.

The following presentation is specifically restricted to those situations in which the observed trap response is such that one can reasonably assume that a randomly placed trap has a relatively high probability of being discovered anywhere near the home range center of an individual. This restriction is largely intuitive and it seems likely that we must deal with gradations in spatial behavior both within and among various species and habitats.

Given an elementary notion of how the individuals of a particular species use space, one can devise theoretical models to predict a temporal pattern of trap response. Observed deviations from the expected led C a l h o un (1964) to postulate the existence of an interspecific hierarchical organization within certain small mammal communities. The presence of a psychologically dominant species with a large home range was 
thought to inhibit the movements of more subordinate and cryptic species, in effect, reducing their probability of locating traps until the remowal of the dominants released the inhibitions. The results presented below are consistent with Calhoun's general thesis of home range inhibition and avoids the complication of a vertical stratification in activity that attended some of his examples. I will use Calhoun's terminology as a convenience but the important aspect with regard to estimating densities is that removal trapping often results in a prompt expansion of home range size.

Home range size and its potential for change during the course of trapping influences both the observed rate of removal and the area from which animals are drawn. In practice, the peripheral traps of a grid may capture relatively more animals than do the inner traps. This pattern, now widely known as "the edge effect", was recognized by earlier students who used grids of live traps but its relevance for estimating densities by the removal method was emphasized in recent years by Ryszkowski, Andrzejewski \& Petrusewicz (1966). These authors recommended what is now known as the sinner square method for estimating densities by discounting both the animals caught and the area associated with the edge of the grid. The general validity of this procedure has been questioned by $\mathrm{Smith}$ et al. (1971).

The inner square method is subject to potential bias. A detailed analysis of variation in both the edge effect and the probability of capture on the inner squares, however, can provide guidelines for evaluating the bias in given situations. Such an analysis is presented below and it seems likely the conclusions can be utilized in other situations if appropriate tests are conducted.

\section{Standard Methods: Terminology}

The characteristics of the Polish Standard Minimum ( $S M$ ) grid (Grodzinski, et al., 1966) are not universally optimal but the major elements provide an appropriate basis from which to derive suitable variations. A shorthand method for designating standard elements and their variations will be useful here and elsewhere.

$S$ (Standard) means the grid is square with an even number of uniformly spaced trapping stations. $M$ is interpreted as the modal distance among those possible for various grids) between stations; i.e. $15 \mathrm{~m}$ is the spacing used in the Polish $S M$ and, historically, is a common unit. A spacing of $15 \mathrm{~m}$ will be assumed by the abbrevation $S M$. For grids with a Ionger station interval, we may use the designation $S L$, with a subscript to indicate the spacing, e.g. $S L_{30}$ means a standard grid with a distance of $30 \mathrm{~m}$ between stations. Similarly, $S S_{7.5}$ designates a standard grid with a short $(7.5 \mathrm{~m})$ station interval.

Viewing a grid as a set of concentric squares, the Polish $S M$ of 256 stations contains eight squares; the innermost is designated as I and the outermost comega, $\omega$ ) in this case is VIII. My standard grids of 64 stations contain four squares and 
can be designated as $S M$ IV in contrast to the Polish $S M$ VIII. The penultimate square is $\omega-1$ and would designate square III in an $S M$ IV grid or square VII in an $S M$ VIII grid.

Dividing an $S M$ grid into four quarters, the number of stations in each quartersquare from I outwards is $1-3-5-7-9 .$. and the cumulative sum of these from I outwards is $1,4,9,16,25, \ldots$ An awareness of these progressions enables one to calculate readily the relative number of traps and the relative areas associated with the various squares.

\section{A MODEL}

For either the total community or for any particular subset thereof (species, age, and sex), a grid of removal traps can generate only two types of information: the distribution of the catch over space, and how this changes with time. Translating this information into estimates of density and range size requires a model specifying expected relationships among the traps and the animals. I will start with a simple model where the system is assumed to be static, with no intra- and inter-specific variation, and then proceed to a more complex model where the system is dynamic with extensive variation. The dynamic or kinetic aspects concern the changes that occur during wshort term " ( $1-5$ days) and "long term * (10-30 days) trapping. The changes of greatest concern include expansion of range size, invasion (movement of previously unexposed animals onto the inner squares) and, possible, reaction toward the bait and trapping device. In general, the above time distinctions separate periods where invasion is minimal for dominant species but may be inadequate for exposing subordinate and cryptic species on one hand and, wherein subordinate and cryptic animals are probably released but invasion by dominants is more likely on the other hand. This distinction, of course, is not intended as a firm prediction. Continual trapping (longer than 30 days) may involve substantial changes related to natural mortality and is hardly appropriate for an instantaneous estimate.

\section{Statics}

The initial assumptions of the model are that all ranges for a particular species are the same size, circular and randomly distributed, that the area within the home range is utilized uniformly, and that no changes in these conditions occur during the course of trapping. Given an appropriate trapping device, all individuals have the same probability of capture and all are caught during the period of study. We can then describe the expected catch per station on a grid of specified dimensions for various home range sizes. T a n a $\mathrm{k}$ a (1972) has also approached the problem of edge effect theoretically but apparently he has focused on the special case where the home range radius $(r)$ and the distance between trapping stations (d) are equal. 
With the above assumptions, the expected distribution of catches could be determined by throwing randomly a large number of circles of given radius at the grid. The probability that a mouse represented by the circle will be caught at any particular station within his range is unity dividied by the number of stations to which he is exposed and the relative number of mice caught at each station is the sum of the probabilities for all exposed mice. I arbitrarily assume a trapping station has a catching radi us of $0.5 \mathrm{~m}$. Other reasonable assumptions would have little effect on the results. Square I of an $S M$ IV rid is $45 \mathrm{~m}$ from $\omega$ and thus not exposed to individuals whose range centers are outside the grid if $r<45 \mathrm{~m}$. In such cases, traf success ( $T S=$ number caught/number of trapping stations) for $I$ is used as the standard and relative TS for all squares is determined by dividing each observed $T S$ by that for I.

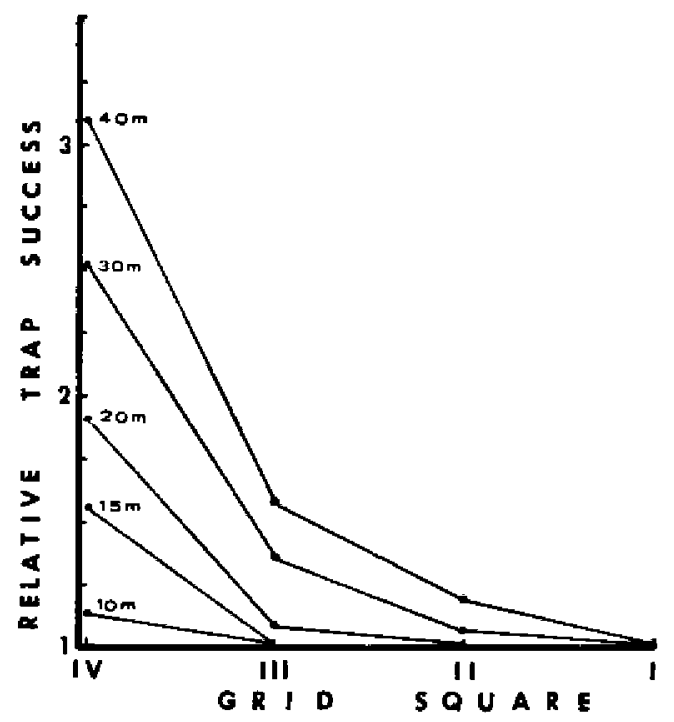

Fig. 1. Expected catch per trap on grid squares (I=innermost, IV=outermost) for populations having different home range radii $(10$ to $40 \mathrm{~m})$ assuming that an individual is equally likely to be caught at any trap within its range and that no behavioral changes take place until all animals originally exposed to the traps are caught. Trap station interval $=15 \mathrm{~m}$.

In practice the above procedure is laborious without a computer and I have arbitrarily assumed that mice are distributed uniformly at $5 \mathrm{~m}$ square intervals (400/ha, or $9.0 /$ trapping station within the grid); the subgrid of mice was begun at coordinates $2.5,2.5 \mathrm{~m}$ from the trap grid. I have tested range radii of $10,15,20,30$, and $40 \mathrm{~m}$ (Fig. 1). The results 
are not mathematically precise but the qualitative relationships are both accurate and adequate for evaluating the fit of results from the field and for theoretical comparisons.

For a home range radius $(r)$ of $10 \mathrm{~m}$ there is very little edge effect and it is apparent that any smaller $r$ would not produce an edge effect. As $r$ increases, so does the relative edge effect. TS is highest at $\omega$ and decreases curvilinearly toward the center. (As $r$ relative to the side of $\omega$ increases, the corner effect is increased.) If the assumptions held, $r$ could be determined by fitting the observed catch to the expected by interpolating intermediate $r$ 's. Note that none of the relationships between $r$ and the edge effect are strictly linear, although they may appear so over short segments.

The consequences of deviations from the assumptions can be examined theoretically for static situations. Instead of circles, we can throw ellipses, rectangles, or irregular shapes having the same area as a circle with radius $r$. It turns out that the shape of the range has no effect on the distribution of catches and we can assume that an estimate of $r$ represents an equivalent area without making any assumptions about shape. The area of effect around the grid, however, will be influenced by range shape. If ranges are elongate, a gradient in residual density will be produced, but the average area of effect will be as if ranges were circular.

If range size varies within the population due to social dominance, sex and age, the consequences of pooling such animals can be determined from Fig. 1. If, for example, $r$ for males is $40 \mathrm{~m}, r$ for females is $20 \mathrm{~m}$, the original sex ratio is $1: 1$ and the grid locations of the individual catches is unknown, the "population" distribution can be had from summing square values for 40 and $20 \mathrm{~m}$ and dividing by 2 . The results for $\omega$ inward are $2.54,1.34,1.1$, and 1.0 , and fit an expected $r$ of $30 \mathrm{~m}$. (Fig. 1.) The observed sex ratio will favor males $1.6: 1$, with the major deviation appearing on $\omega$. Repeating the procedure for $r$ 's of 30 and $10 \mathrm{~m}$ approximated the results for $20 \mathrm{~m}$, and we can conclude that, above $r=10 \mathrm{~m}$, a reasonable variation in range size among the exposed population will have little influence on determining the mean.

If, instead of using all parts of their range equally, animals tend to be trapped near the center ( $\mathrm{H}$ a y n e, 1949b; C a l houn \& C a s by, 1958; $\mathrm{Harris}$ an, 1958) the filter effect of $\omega$ will be enhanced, preventing most animals whose ranges centered outside the grid from penetrating to the inner squares and limiting the edge effect to $\omega$, at least at ranges less than the equivalent of $30 \mathrm{~m}$. If animals are distributed in patches instead of either randomly or uniformly, serious biases can be produced and any conclusions based on a fit to the model will be erroneous. 


\section{Kinetics}

At least theoretically, the above deviations from the initial assumptions have little influence on the usefulness of the model but to examine the kinetics of the system, we must make an assumption concerning the daily probability of catching animals $(p)$. For animals with a given range size, I assume that $p$ is proportional to the number of trap stations included in the home range. Thus, if $r=20 \mathrm{~m}$, animals whose ranges are entirely within the grid will be exposed to an average of 5.6 stations ( $H R$ area $=0.126 \mathrm{ha}$; station density $=44.4 / \mathrm{ha}$ ). With circular ranges, some animals will be exposed to as few as four stations and some to as many as seven, but these extremes are in the minority; in this case, we can ignore the variations since the results will be little affected. Ignoring the small edge effect on $\omega-1$ (Fig. 1), and assuming that animals located

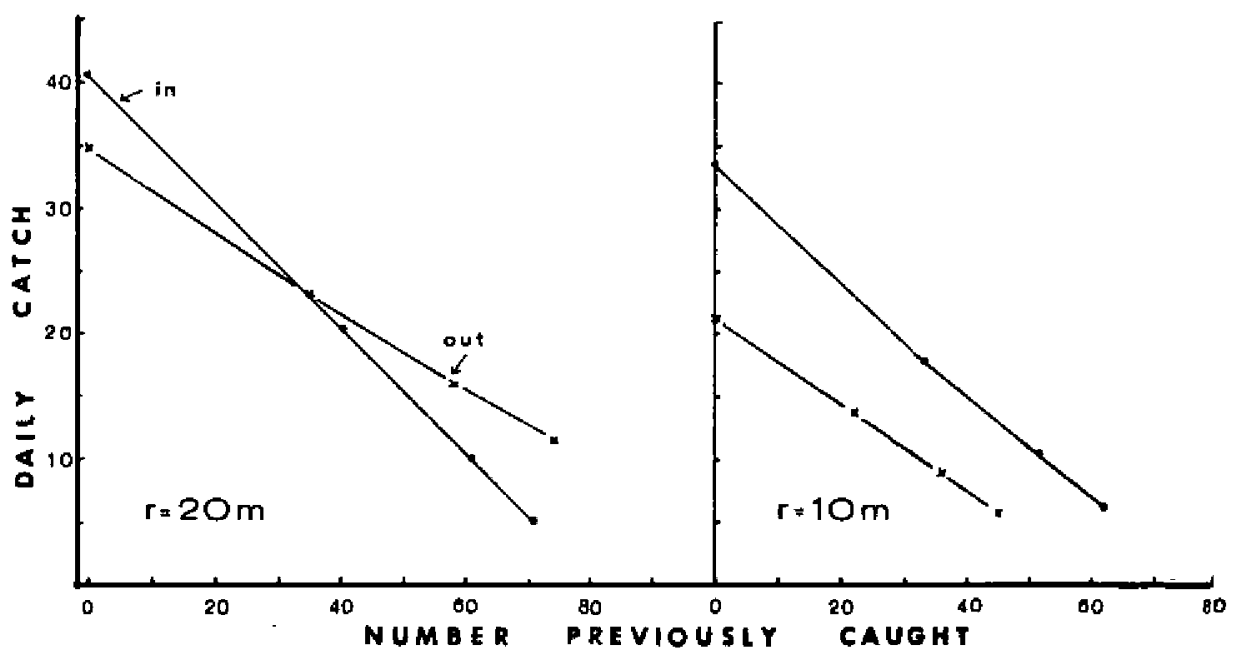

Fig. 2. Expected rates of capture on inner (I-III, -) and outer IV, $X$ ) grid squares as influenced by home range radius $(\tau)$ and exposure to different numbers of traps within each radius. See text and Table 1 for assumptions and procedures.

midway between $\omega$ and $\omega-1$ are equally divided between $\omega$ and $\omega-1$, a density of 400 mice/ha puts 81 animals at risk on a quarter section of the inner squares. Arbitrarily assuming a value of $p=0.5$ for animals exposed to 5.6 stations, the expected sequence of captures $\left(C_{1}\right.$ to $\left.C_{4}\right)$ can be plotted according to the Hayne (1949a) method (Fig. 2). The estimated number $(\hat{N})$ from four days of trapping, of course, is 81 , ard $\hat{p}=0.5$ is retrieved by $C_{1} / \hat{N}$.

Animals whose range centers are at progressively greater distances from 
Table 1

Theoretical patterns of capture for small mammals on the inner (I-III) and outer (IV) quarter-squares of an SM IV grid as influenced by the distance of home range centers from the grid. All home ranges assumed to be circular with $\tau=20 \mathrm{~m}$, the probability of capture $(p)$ is proportional to trap exposure, and the outer square is a perfect filter. $D=400 /$ ha.

\begin{tabular}{|c|c|c|c|c|c|c|c|c|c|c|c|}
\hline & \multirow{2}{*}{$\begin{array}{c}\text { Outward } \\
\text { Distance from } \\
\text { Square III, m }\end{array}$} & \multirow{2}{*}{$\begin{array}{l}\text { Mean No. of } \\
\text { Traps to which } \\
\text { Animals are } \\
\text { Exposed }\end{array}$} & \multirow{2}{*}{$\begin{array}{c}\text { Assumed } \\
p\end{array}$} & \multirow{2}{*}{$\begin{array}{l}\text { No of } \\
\text { Exposed } \\
\text { Animals }\end{array}$} & \multicolumn{5}{|c|}{ Expected Catch } & \multirow[b]{2}{*}{$\hat{p}$} & \multirow[b]{2}{*}{$\hat{N}$} \\
\hline & & & & & $c_{1}$ & $C_{2}$ & $C_{3}$ & $C_{4}$ & $T_{4}$ & & \\
\hline Inner Squares & -37.5 to 7.5 & 5.6 & 0.500 & 81 & 40.5 & 20.3 & 10.1 & 5.1 & 76.0 & 0.50 & 81 \\
\hline Outer Square & $\begin{array}{r}7.5 \\
12.5 \\
17.5 \\
22.5 \\
27.5 \\
32.5 \\
7.5 \text { to } 32.5\end{array}$ & $\begin{array}{l}5.1 \\
4.9 \\
4.2 \\
2.5 \\
2.2 \\
1.4\end{array}$ & $\begin{array}{l}0.455 \\
0.438 \\
0.3^{-5} \\
0.223 \\
0.196 \\
0.125\end{array}$ & $\begin{array}{r}9 \\
20 \\
22 \\
24 \\
26 \\
25 \\
126\end{array}$ & $\begin{array}{r}4.1 \\
8.8 \\
8.3 \\
5.4 \\
5.1 \\
3.1 \\
34.8\end{array}$ & $\begin{array}{r}2.2 \\
4.9 \\
5.2 \\
4.2 \\
4.1 \\
2.7 \\
23.3\end{array}$ & $\begin{array}{r}1.2 \\
2.8 \\
3.2 \\
3.2 \\
3.3 \\
2.4 \\
16.1\end{array}$ & $\begin{array}{r}0.7 \\
1.6 \\
2.0 \\
2.5 \\
2.6 \\
2.1 \\
11.5\end{array}$ & \begin{tabular}{r|}
8.2 \\
18.1 \\
18.7 \\
15.3 \\
15.1 \\
10.3 \\
85.7
\end{tabular} & 0.31 & 110 \\
\hline All Squares & -37.5 to 32.5 & & & 207 & 75.3 & 43.6 & 26.2 & 16.6 & 161.7 & 0.40 & 194 \\
\hline
\end{tabular}


$\omega-1$ will be exposed to progressively fewer traps. Those animals most distant from the grid in our model are exposed to an average of 1.4 stations, and thus $p=0.125$ (Table 1). The expected sequences of capture on $\omega$ can be estimated by summing the expected catches of animals at various distances from $\omega-1$ and the results are plotted in Fig. 2. The slope of the line is not linear but if, in practice, it were assumed to be linear, $N$ approximates 110 instead of 126 , and $\hat{p}$ appears to be $34.8 / 110=0.316$. Pooling the catch from all squares yields $\hat{N}=184$ vs. the 207 actually exposed and this estimate is further from the mark than is the sum of the separate estimates $(81+110=191)$. Pooling animals that have different probabilities of capture inevitably underestimates $\mathrm{N}$ and, on theoretical grounds $C_{\omega}$ should not be used to estimate $D$.

Additional theoretical insights can be provided by examining results expected if $r=10 \mathrm{~m}$. Animals inside the grid will be exposed to an average of 1.4 stations. Approximately $1 \%$ of the mice will not be exposed to any traps, depending on chance and the shape of the range. In general. however, 0.6 will be exposed to one set and 0.4 to two sets if ranges are circular. In this case, the expected differences in $p$ are more important and we can arbitrarily assign $p=0.6$ to animals exposed to two sets and $p=0.3$ to animals exposed to one set. Proceeding as in the previous example, the estimate for the inner squares is 75 instead of 80 (one animal not exposed), and the apparent $\hat{p}=0.45(33.6 / 75)$. For animals exposed to $\omega, 84 \%$ are at risk to a single set and the average is 1.17 . The deviation irom linearity is not perceptible. The estimate of 61 (Fig. 2) is close to the 64 mice originally exposed and apparent $\hat{p}=0.35$. In comparison with the results for $r=20 \mathrm{~m}$ (Fig. 2), the slopes of the inside and outside lines are less deviant. At $r_{i}=7 \mathrm{~m}$, there is no edge effect and no difference in $\hat{p}$ should be observed: the deviation increases with range size.

While the relationships in Fig. 1 seem intuitively simple, estimating relative trap success on the grid squares is not so simple, even if mo changes in behavior occur. If $p$ varies for animals with the same range size because of their location with reference to the grid, both the observed and the estimated relative number on $\omega$ will be too low. While we could proceed theoretically by making assumptions concerning the behavioral responses of survivors to the removal of their associates, an examination of some empirical results is more appropriate. 


\section{AN EXAMPLE: INTRODUCTION}

\section{Area and Methods}

The tropical Pacific island of Guam provides excellent conditions for testing field methods. Except for a few Norway rats closely associated with buildings, the terrestrial small mammal fauna contains only four species: The house shrew (Suncus murinus), the roof rat (Rattus rattus), the Polynesian rat (R. exulans), and the house mouse (Mus musculus). With the exception that house mice are not known to inhabit forests, all four species are essentially ubiquitous. Habitat patchiness has relatively little effect on community composition. The work reported here was conducted primarily in simple biotopes - meadows, fields, and open savanna where the possibility for a vertical stratification of activity by small mammals is minimal. While individuals may travel the lines of least resistance through vegetation, runways are not apparent. Guam normally has pronounced wet and dry seasons but all species can breed the year around: thus, compared to many temperate areas, conditions are relatively uniform and stable.

SM IV grids were established in twelve localities on Guam and trapped from one to four times each during the period May 1962 to May 1964 for a total of 25 trappings. Two $S L_{30}$ IV grids were trapped a total of six times and one $S L_{43} \mathrm{~V}$ grid was trapped once. The duration of trapping ranged from a normal four days to 30 days. Each trapping station contained two rat-sized $(85 \times 180 \mathrm{~mm})$ snap traps plus one or two smaller traps (mouse, $47 \times 98 \mathrm{~mm}$ and Museum Special, $70 \times 135 \mathrm{~mm}$ ). All were baited with fresh coconut and bait was replaced as necessary.

\section{Analytical Procedures}

For each species, the basic information produced by a grid of removal traps is the catch on each square and how this changes with time. Theoretically, the daily catch should decline exponentially and, where this expectation is approximated, $\hat{N}$ and $\hat{p}$ can be estimated by either H a y ne's (1949a) graphical method or Z i p pin's $(1956,1958)$ multinomial method. If these methods are deemed appropriate, then calculations can be simplified for short-term trapping by pooling the catch for the first two days $\left(C_{1,2}\right)$ and second two days $\left(C_{3}, 4\right)$. For results with a perfect fit to the exponential, the probability of avoiding capture, $\hat{q}=1-\hat{p}=$ $=C_{2} / C_{1}\left(\mathrm{C}\right.$ a 1 houn \& Cas by, 1958). Since $\hat{q}^{2}=C_{3}, 4 / C_{1}, 2$, then $\hat{q}, \hat{p}$, and $\hat{N}=T /\left(1-\hat{q}^{\mathrm{k}}\right)$ or $\hat{N}=C_{1,2} /\left(1-C_{3}, 4 / C_{1}, 2\right)$ can be calculated easily with a slide rule without reference to either the graphs of $\mathrm{Zippin}$ 
$(1956,1958)$ or the tables of Janion, Ryszkowski \& Wierzbow$s \mathrm{k} \mathrm{a}(1968)$. $T=$ the total catch and $k=$ the number of days $=4$ in my case. When either $C_{1}$ is lower or $C_{4}$ is higher than expected, the averaging process appears to give results for $\hat{N}$ that are intuitively more accurate for the inner squares than would be obtained otherwise.

In practice, behavioral changes within the community during the course of trapping may produce marked deviations from the assumption of a constant $p$. At the extreme, the daily catch may either remain constant or even increase. Calculating either $\hat{p}=0$ or a negative $\hat{p}$ in such cases is irrational, yet some statistic describing the observed rate of capture $(R C)$ is desirable. I will use $R C=1-\hat{q}$, where $q$ is defined as the inverse ratio of sequential catches, i.e., either $C_{2} / C_{1}$ or, as $I$ use it, the square root of $C_{3,4} / C_{1}, 2$. This statistic is an appropriate estimator of $\hat{p}$ only when $q$ is substantially less than unity.

$R C$ may be calculated for any combination of days that seems appropriate for comparative purposes if the method is internally consistent. $R C$ will approximate $\hat{p}$ only under special conditions, however, and $R C$ should not be confused with $Z$ i p p i n's (1956) $R_{\kappa}$.

\section{HOME RANGE SIZE AND RATE OF CAPTURE}

\section{Distribution of Catches on Squares}

For an $S M$ grid, my model predicted that relative trap success (TS) on each inner square would be 1.0 while that on $\omega$ should be a function

Table 2

Relative trap success for animals caught on each grid square (I-IV), using the catch on III as a standard (1.0). TS=4-day catch/number of traps. Values are for 24 grids.

\begin{tabular}{lccccc}
\hline \multicolumn{1}{c}{ Species } & I & II & III & IV & $N$ \\
\hline Suncus & 0.71 & 0.93 & 1.00 & 1.81 & 749 \\
$R$. rattus & 1.21 & 1.06 & 1.00 & 1.58 & 507 \\
$R$ exulans & 1.37 & 0.85 & 1.00 & 1.31 & 371 \\
Mus & 0.86 & 1.05 & 1.00 & 1.78 & 150 \\
TOTAL & 1.01 & 0.96 & 1.00 & 1.62 & \\
$N$ observed & 89 & 252 & 440 & 996 & 1777 \\
$N$ expected & 88 & 264 & 440 & 617 & 1409 \\
\hline
\end{tabular}

of range size, assuming $\omega$ acts as a filter. This general prediction can be tested initially by pooling results from $23 S M$ IV grids, each trapped for four days (Table 2). For comparative purposes, the relative $T S$ for eack. 
species caught on each square was determined by using the catch on III as the standard (TS =1.0) The catches on I and II were too low to provide a reliable standard but the observed values for each species approximated the expected - the small deviations not being statistically significant. The relative $T S$ on $\omega$ was substantially larger than 1.0 , suggesting that ranges averaged larger than $r=10 \mathrm{~m}$ for all four species.

Since the observed edge effect was essentially limited to $\omega$ and the ratio of traps on the outer square $(\omega)$ to those on the inner three squares (I) is 7:9, relative $T S_{\omega}=1.29 C_{\omega} / C_{\mathrm{I}}$. Relative $T S_{\omega}$, however, increased with the duration of trapping on SM IV grids (Table 3). Some increase is predicted from the model (Fig. 2) but the observed increase generally exceeded the expected, dramatically so for Mus.

Where a trap spacing of $30 \mathrm{~m}$ was used (Table 3), no obvious edge effect was observed on day-1, suggesting that $r$ averaged less than $20 \mathrm{~m}$. However, an edge effect developed with time, raising questions as to the relationships between the observed edge effect and home range size.

\section{Rates of Capture by Grid Squares}

The relative numbers of shrews caught on the outer squares of SM IV grids varied greatly from grid to grid and at different times in the same field, implying a comparable variation in range size. The effects

Table 3

Variation in relative trap success on the outer grid square as a function of duration of trapping, distance between traps, and species.

\begin{tabular}{|c|c|c|c|c|}
\hline & Suncus & R. rattus & R. exulans & Mus \\
\hline \multicolumn{5}{|c|}{$15 \mathrm{~m}$ spacing, 23 grids } \\
\hline Day-1 & 1.51 & 1.39 & 1.23 & 1.10 \\
\hline Day-4 & 3.00 & 2.10 & 1.51 & $3.85^{\mathrm{a}}$ \\
\hline 4-Day Total & 1.85 & 1.57 & 1.29 & 1.93 \\
\hline Total Nb & 704 & 513 & 340 & 115 \\
\hline \multicolumn{5}{|c|}{$30 \mathrm{~m}$ spacing, 6 grids } \\
\hline Day-1 & 1.05 & 0.98 & 0.93 & $0.93 \mathrm{c}$ \\
\hline $\mathrm{J}$ ay -4 & 2,00 & 1.45 & 1.14 & 2.38 \\
\hline 4-Day Total & 1.15 & 1.19 & 1.09 & 1.78 \\
\hline Total $N$ & 228 & 165 & 227 & 108 \\
\hline
\end{tabular}

a Calculated for Day-3 when the value was maximal for Mus.

b Total $N$ 's vary slightly among tables and figures because data from some grids were inappropriate for certain analyses.

c Values for Mus supplemented with the catch from a grid with a spacing of $22 \mathrm{~m}$.

of range size on patterns of capture (Fig. 3) were determined by rank ordering the samples according to the relative catch on $\omega$ and dividing the array into two equal groups representing small and large ranges (one 
grid being excluded because no shrews were caught on day-1. In both cases, (Fig. 3), both the daily probability of capture $(\hat{p}=0.40$ and 0.43$)$, and the total number of animals caught on the inner squares $\left(T_{\mathrm{I}}=142\right.$ and 145) were similar. The inner catch sequence for small ranges curves appreciably, suggesting that some change in behavior has altered $p$ and calculating $R C_{I}=0.35$ may be more appropriate. Since the inner slope for large ranges is essentially linear, there is no evidence for measurable invasion through day-4.

When ranges were large, $R C_{w}$ was essentially identical to the inne: rate for the first three days. $C_{4}$ for $\omega$ (and to a lesser extent, $C_{3}$ ) is high, and indicates a change in behavior after the first two days: animals from the outside seem to have been attracted to the grid but most have been

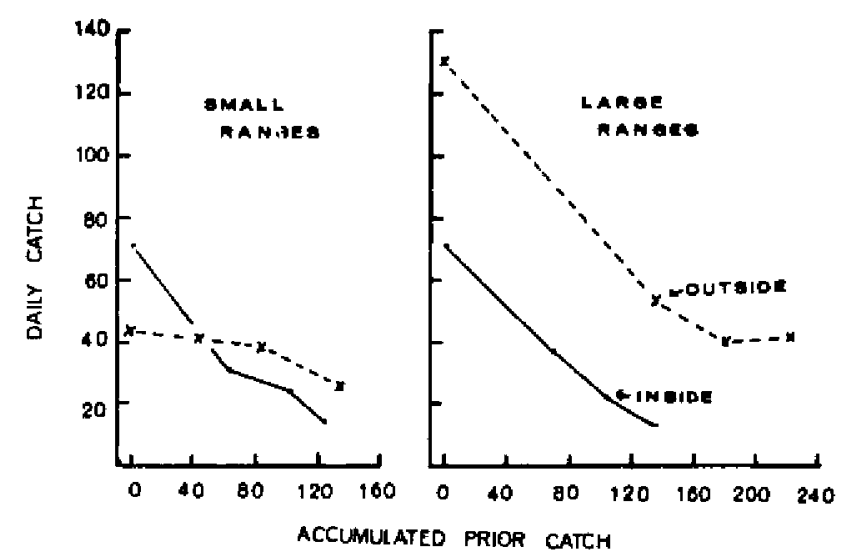

Fig. 3. Observed rates eapture on inner (I $-I I I,+)$ and outer (IV, $X$ ) grid squares for Suncus populations having small and large home ranges. Values are totals for eleven grids of each home range class; classes being arbitrarily defined by dividing the distribution at the midpoint.

intercepted at the margin. Where ranges were small, the number of shrews caught on $\omega$ decreased but little with time $(R C=0.12)$.

For both classes of range size, the results on $\omega$ are contrary to those predicted by the model (Fig. 2). The trap response of animals with large ranges differs from those with small ranges and a static model is of no direct use in evaluating the results even when differences in the initial $p$ are considered. Since the observed behavioral changes are a function of range size, the most reliable home range index $(H R I)$ is $f \cdot C_{\omega} / C_{I}$ for day-1, where $f$ is the ratio of inside to outside traps (e.g. 1.29 for $S M$ IV and 3.27 for $S M$ VIII grids.) 


\section{Home Range Expansion}

The concept of an expanding range, as originally postulated by Calh oun (1964) to explain the lag in capture for certain species, remains controversial (e.g. $\mathrm{K}$ a $\mathrm{ufm}$ a $\mathrm{n}$, et. al., 1971). While alternative hypotheses such as neophobia (avoidance of strange objects) and invasion may both be plausible and actually in effect under some circumstances, most of the observations on Guam are consistent with Calhoun's thesis and the alternatives, in general, are either unnecessary or are inconsistent with the observations.

For each of the three larger species, the $S M$ IV grids were rank ordered by the $H R$ index and divided into five subsamples, each as equally as possible. For each subsample, the mean $H R$ index and the mean $R C$ for

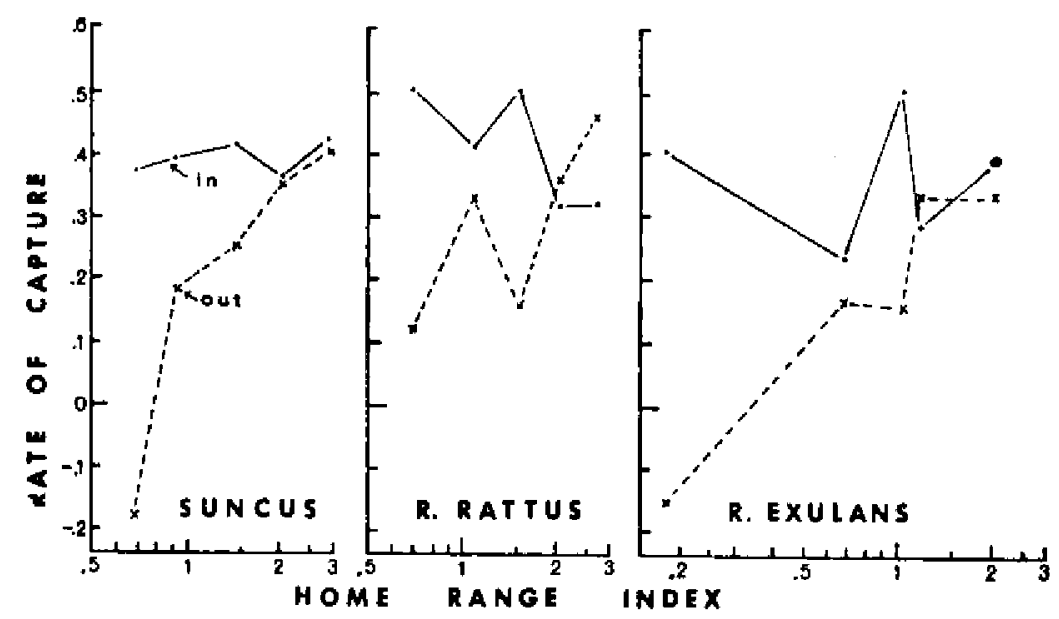

Fig. 4. Mean rate of capture on the inner (I - III, , ) and outer (IV, $X$ ) squares of grids in relation to the home range index for $S$ uncus (22 grids, $n=694$ ), $R$. rattus (22 grids, $\mathrm{n}=513$ ) and $R$. exulans (19 grids, $\mathrm{n}=358$ ). See text for definitions and methods of estimation.

the inner and outer squares was calculated (Fig. 4). In general, as range size increases, so does $R C_{\omega}$, reaching a maximal value of about 0.4 for all three species. This is consistent with the idea of an expanding range, i.e., the smaller the initial range, the lower the probability of encountering a trap on day- 1 and the greater will be the relative numbers taken on days 2 to 4 as ranges expand, giving a minimal $R C$. When range size is maximal on day-1, no expansion occurs and the $R C$ is maximal because new animals are not exposed as trapping proceeds.

Some unanticipated results appear in Fig. 4, however: 1) The $H R$ index for all three species falls substantially below the expected minimum of 
1.0 on several grids each, and 2) $R C_{I}$ for Suncus and $R$. exulans fluctuates about a mean value of approximately 0.4 , while that for $R$. rattus declines.

Assuming the correctness of Calhoun's model, the only assumption necessary to explain the low $H R$ indices is that animals inside the grid expand their initially small ranges very quickly (i.e., on day-1) in response to the removal of neighbors. The $\omega$ square, in effect, resembles a line of traps on its external aspect and I have shown (B a r beh en $n$, 1969) that lines of traps "release subordinate species more slowly than do $S M$ grids. Thus, a lag in catch may be present on $\omega$, but not internally, and the release follows a wave-like pattern from the inside to progressively greater distances outside the grid as trapping proceeds.

The relative magnitude of the changes required to produce the postulated process of range expansion can be estimated by attempting to model the conditions producing an $H R$ index of 0.69 for Suncus (Fig. 4). Apparently $r$ is less than $9 \mathrm{~m}$ so I will guess at $7 \mathrm{~m}$. If, on day-1, $r$ on the inside expands to $10 \mathrm{~m}$, essentially all animals from $8100 \mathrm{~m}^{2}$ will be exposed to traps. There are 28 sets of traps on $\omega$, and if $r$ equals $7 \mathrm{~m}$ then the shrews from an area of $4310 \mathrm{~m}^{2}$ will be exposed to traps. If $p$ is the same for all animals exposed to traps, then the ratio of the outside: inside catches on day-1 will be $4310: 8100$, giving an $H R$ index of 0.684 . This equals the observed value, making the explanation plausible. In order to produce an $R C$ of -0.18 on $\omega$, it is only necessary to postulate that $\tau$ expands from $7 \mathrm{~m}$ to about $18 \mathrm{~m}$ by day-4. Since $r$ has been estimated at up to $30 \mathrm{~m}$ for Suncus by both removal grids and live trapping (see IV below) expansion to $18 \mathrm{~m}$ is reasonable. The results from experiments in trap spacing, however, are more convincing.

\section{Effects of Trap Spacing}

The original logic of using grids with various spacings was that the rate of release of subordinate animals should be a function of the rate at which dominants are removed. This should depend on trap spacing ( $B$ a $r$ behe $n n, 1969$ ). In addition, I wanted to increase confidence in my estimates of density so a usual practice during the first year of work was to shift all traps on line to a point halfway between each original station after two days of trapping. This was done to expose any animals that were not exposed to the original set because of small ranges. The results of this experimentation follows.

For nine SM IV grids where traps were shifted and for 14 where they were left in place, the catch on the inner squares during the first two days was compared with that on the second two days. Of 300 shrews 
caught, the deviation from the expected contingency cell values was only $2.1\left(\chi^{2}<1.0\right)$. With a trap spacing of $15 \mathrm{~m}$, virtually all shrews were exposed to traps during the first two days; shifting the traps did not expose significant numbers of new animals. On grids with a spacing of $30 \mathrm{~m}$, shifting traps did expose significant numbers of new animals. For two $S L_{30}$ grids where traps were shifted, the inside catches of shrews for the two two-day periods was 21 and 20; for four grids where traps were not shifted, the catch was $44-17\left(\chi^{2}=4.7, \mathrm{p}<\cdot 05\right)$. Similar results were obtained for $R$. rattus. Trap spacing influences the proportion of the population which is exposed.

A better appreciation of the pattern of capture relative to trap spacing can be observed in those few areas where the duration of trapping

Table 4

The influence of trap spacing on the sequence of capture for inner squares. Expected values for the catch on days 5 and $6\left(C_{5}, 0\right.$ assumes that the observed rate capture for the first four days remains constant.

\begin{tabular}{|c|c|c|c|c|c|c|c|}
\hline \multirow[b]{2}{*}{ Species } & \multirow{2}{*}{$\begin{array}{c}\text { Trap } \\
\text { Spacing }\end{array}$} & \multirow{2}{*}{$\begin{array}{l}\text { No. of } \\
\text { Grids }\end{array}$} & \multicolumn{3}{|c|}{ Catch per two-day period } & \multirow{2}{*}{$\begin{array}{c}\text { Expected } \\
C_{5,6}\end{array}$} & \multirow{2}{*}{$\begin{array}{l}\text { 4-day rate } \\
\text { of Capture }\end{array}$} \\
\hline & & & $C_{1,2}$ & $C_{3,4}$ & $C_{5.8}$ & & \\
\hline Suncus & $\begin{array}{l}15 \\
30 \\
43 \\
15\end{array}$ & $\begin{array}{l}5 \\
5 \\
1 \\
5\end{array}$ & $\begin{array}{l}47 \\
49 \\
29 \\
17\end{array}$ & $\begin{array}{r}19 \\
20 \\
16 \\
2\end{array}$ & $\begin{array}{r}9 \\
20 \\
15 \\
5\end{array}$ & $\begin{array}{l}7.6 \\
8.1 \\
8.7 \\
0.2\end{array}$ & $\begin{array}{l}0.36 \\
0.36 \\
0.26 \\
0.66\end{array}$ \\
\hline R. rattus & $\begin{array}{l}30 \\
43 \\
15\end{array}$ & $\begin{array}{l}\mathbf{5} \\
1 \\
5\end{array}$ & $\begin{array}{l}36 \\
36 \\
49\end{array}$ & $\begin{array}{l}15 \\
16 \\
19\end{array}$ & $\begin{array}{r}12 \\
4 \\
8\end{array}$ & $\begin{array}{l}6.2 \\
6.9 \\
7.3\end{array}$ & $\begin{array}{l}0.36 \\
0.33 \\
0.38\end{array}$ \\
\hline R. exulans & $\begin{array}{l}30 \\
43\end{array}$ & $\begin{array}{l}5 \\
1\end{array}$ & $\begin{array}{l}47 \\
29\end{array}$ & $\begin{array}{l}48 \\
27\end{array}$ & $\begin{array}{l}26 \\
24\end{array}$ & $\begin{array}{l}49.0 \\
25.2\end{array}$ & $\begin{array}{r}-0.01 \\
0.04\end{array}$ \\
\hline
\end{tabular}

extended to at least six days. The results from the inner squares of five $S M$ IV grids, five $S L_{30}$ IV grids and one $S L_{43} \mathrm{~V}$ grid are summarized by species in Table 4. For Suncus and $R$. rattus at all trap spacings and for $R$. exulans at $15 \mathrm{~m}$, there were no significant differences in $R C$. The point of interest for these samples is the relative numbers caught on days 5 and 6. For Suncus and R. exulans at a spacing of $15 \mathrm{~m}$, the numbers expected had $\hat{p}$ remained constant are very similar to the observed values. The numbers of $R$. rattus at $15 \mathrm{~m}$ are too small to merit much attention, although some invasion is suggested. (Additional detail on these SM IV grids is provided by Figs. 5-9 and the pooled data include some results that are aberrant, causing $R C$ to be below average for Suncus).

At spacings of 30 and $43 \mathrm{~m}, C_{5,6}$ for Suncus equalled $C_{3,4}$ suggesting that previously unexposed animals (whose presence had been revealed on other occassions by shifting traps) were expanding their ranges. 
Invasion from the outside is an unlikely explanation since it was not observed on $S M_{15}$ grids for Suncus and $R$. exulans where it would be more likely. A similar pattern is seen for $R$. rattus at $30 \mathrm{~m}$ but, at $43 \mathrm{~m}$, the catch continued to decline. Presumably $r$ for $R$. rattus in this particular population was well above average.

A pattern is evident for $R$. exulans, which generally has the smallest range (see below). At a spacing of $15 \mathrm{~m}$ there is no apparent lag in capture; at $30 \mathrm{~m}$ the lag is evident on days 3 and 4 , after which the catch declines; and at $43 \mathrm{~m}$ the lag persists at least through days 5 and 6 , implying that expansion is still taking place. When ranges are very small, any increase will have a great effect on $R C$. Large ranges apparently expand more slowly. The effect may not be noticeable in short term trapping and, if no expansion occurs, a declining catch will be observed.

In the $S L_{43}$ grid, no expansion was evident for $R$. rattus for the first 6 days, Suncus expanded on days 5 and 6, and R. exulans expanded on days 3 and 4 . The grid was trapped for a total of 30 days, producing an additional $44 R$. rattus $(+79 \%)$, 65 Suncus $(+108 \%)$, and $109 R$. exulans $(+136 \%)$ on the inner squares $\left(\chi_{2}=4.76^{*}\right.$ for $R$. rattus versus $R$. exulans). While we cannot discount all possibilities of invasion over this period of time, the observation suggests that the relative number removed during the first six days was proportional to the original range size and that the effect of expansion was inversely related to the original range size.

\section{The Probability of Encountering Traps}

The fact that $R C$ for Suncus and $R$. exulans on the inner squares was independent of range size (Fig. 4) is an unexpected observation. Most animals with a range radius of $9 \mathrm{~m}$ or less are exposed to a single set of traps while animals with $r=30 \mathrm{~m}$ are exposed to a dozen sets. At first glance, one would anticipate significant differences in the probability of encountering a trap. Probabilities of encountering, detecting and accepting traps are functions of searching rates, perception swaths and receptive states of the animals - subjects about which we are profoundly ignorant for free ranging small mammals. However, the only assumption necessary to explain the independence between $R C$ and $\hat{r}$ is that time spent in foraging is independent of range size. •

The daily discovery rate of traps (DDR) equals the number of trap stations per unit area multiplied by the foraging rate $(F R=$ time spent in searching a unit area) multiplied by the time spent in foraging each day $\left(t_{f}\right)$. If an $S M$ station is considered to occupy $1 \mathrm{~m}^{2}$, the density of traps is $1 / 225 \mathrm{~m}^{2}$. We assign arbitrary values to the other variables: A foraging mouse spends 6 sec. $(0.1 \mathrm{~min})$ searching each $\mathrm{m}^{2}$ and forages 
for a total of $2 \mathrm{hr}$ per day $(120 \mathrm{~min})$. Substituting in the equation, $D D R=1$ trap $/ 225 \mathrm{~m}^{2} \times 1 \mathrm{~m}^{2} / 0.1 \mathrm{~min} \times 120 \mathrm{~min} /$ day $=5.3$ traps per day. An animal with $r=10 \mathrm{~m}$ will be exposed to an average of 1.4 traps and each will be visited 3.8 times. An animal with $r=20 \mathrm{~m}$ will be exposed to 5.6 traps and, if foraging routes are not retraced, all might be discovered. An animal with $r=30 \mathrm{~m}$ might be exposed to 12.6 traps, though less than half might be found on any particular night under the assigned values. If the assigned values were realistic we might conclude that the animals were neophobic, i.e., $\hat{p}$ is less than 0.5 despite a $D D R$ of 5.3 . If an individual spends an average of $1 \mathrm{~min}$ in searching each $\mathrm{m}^{2}$ for insects, seeds, and other food, $D D R$ becomes 0.53 and we can dispense with any notion of neophobia. Values for $F R$ and $t_{f}$ are essentially unkown.

The model can be refined (e.g., $\mathrm{S} \mathrm{ch}$ oe $\mathrm{ne} \mathrm{r}, 1971$ ) by including time taken to consume food, patchiness in the distribution of foraging areas, opportunistic feeding (i.e., accepting especially attractive foods encountered while engaged in other activities) and other considerations, but the basic conclusion remains: If the duration of foraging and associated behavior is independent of range size, $R C$ for exposed animals on the inner squares is also relatively independent of range size.

The inverse relationship between $R C$ on the inner squares and range size for $R$. rattus is more perplexing (Fig. 7). The low values for $R C$ were generally associated with exceptionally high values for $C_{2}$. This would suggest an expansion of range but ranges were already large. Apparently, when ranges are large, $R$. rattus tends to overrun $\omega$, i.e., either invasion occurs or the filter breaks down. In either case, densities on the inner squares will be overestimated. Clearly not all species can be expected to behave precisely like those which produce a good fit to the model. This, however, can hardly be determined with fewer replicates than those available here. To summarize, the initial home range size mainly determines what proportion of the animals are originally exposed, not how fast they are caught. The apparent rate of capture will remain constant unless ranges expand after day-1.

\section{Mus and Neophobia}

The house mouse has generally been ignored in the above accounts, both because of the paucity of adequate samples and because Mus may be classed as a "difficult * species on Guam-lags in capture are common. I have treated captures for Mus by dividing them into two-day periods for analysis (Table 5). On five grids Mus showed a strong lag in capture, none being taken in the first two days. A comparison of inside and outside catches suggests a small range. Mean density apparently was on the 
order of 2/ha. Samples classed as having large or small ranges on the basis of the catch on the first two days have similar rates of capture on the inner squares - the rates being very similar to those of the three larger species (Fig. 4). The rates of capture on the outer squares, however, differed from each other significantly $(p<0.05)$, with the catch of Mus increasing with time when ranges were small. The latter observation is consistent with the result described for Suncus (Fig. 3) and merely represents a more extreme average condition: Increasing catches on the outer square have been observed for Suncus and $R$. exulans (i.e., Fig. 4 where $R C<0.0$ ).

Pooling samples into various classes results in an increasing probability of misclassification as sample size declines and the results may be faulty. Lacking a single adequate sample from an SM IV grid on Guam, the process of radial unfolding for $M u s$ can be illustrated with an $S M$ IV grid from Saipan in 1962. The four day sequence of captures on the

Table 5

Patterns of capture for Mus on SM IV grids.

\begin{tabular}{|c|c|c|c|c|c|c|c|c|}
\hline \multirow[b]{2}{*}{ Characteristic } & \multirow{2}{*}{$\begin{array}{l}\text { No. of } \\
\text { Grids }\end{array}$} & \multicolumn{4}{|c|}{ Inside Catch } & \multicolumn{3}{|c|}{ Outside Catch } \\
\hline & & $c_{1,2}$ & $C_{3,4}$ & $R C$ & $N /$ ha & $C_{1,2}$ & $C_{3,4}$ & $R C$ \\
\hline Strong lag & 5 & 0 & 8 & $-\infty$ & $2+$ & 0 & 6 & $-\infty$ \\
\hline Small range & 6 & 12 & 4 & 0.42 & 3.7 & 5 & 11 & -.48 \\
\hline Large range & 10 & 15 & 7 & 0.32 & 3.5 & 29 & 18 & 0.21 \\
\hline
\end{tabular}

inside was 6, 7, 7 and 4, suggesting a gradual expansion of range through day- 3 . The catch on the outer square was $0,2,1$, and 7 , showing the effect of the lag in release associated with the periphery.

Is neophobia necessary to explain those cases where no mice were caught on day-1? Such observations were usually associated with a low total catch of the species in question over a 4-day period, implying a low density but with uncertain reliability. An exception is provided by the catch of 24 mice on the inner squares of an $S L_{30}$ IV grid. Over an eightday period the daily sequence of captures was $0,3,3,3,8,1,5$, and 1 . Trap spacing provides one set for each $900 \mathrm{~m}^{2}$. Assuming there were actually 30 mice living inside the grid and that $\tau$ approximated $5 \mathrm{~m}$, the probability that a trap placement would coincide with a mouse range is 0.087 . On the average, then, two or three mice should have been exposed to traps initially and if the probability of capture for those animals is about 0.5 , then we would expect to catch one or two on the first day. The fact that none was actually caught may have been influenced by trap avoidance, but the need to postulate such a behavior is not very strong.

In general, the trap response of $M u s$ is similar to that of the larger 
species where range sizes are comparable. While I cannot contend that $R$. exulans, for instance, is lacking in some level of neophobia, this characteristic is unlikely to have much bearing on the rate of capture observed as a function of range size and trap spacing (Tables 3 and 4). One might argue that larger ranges reduce the effects of neophobia by repeatedly exposing the animals to the strange objects but, if the

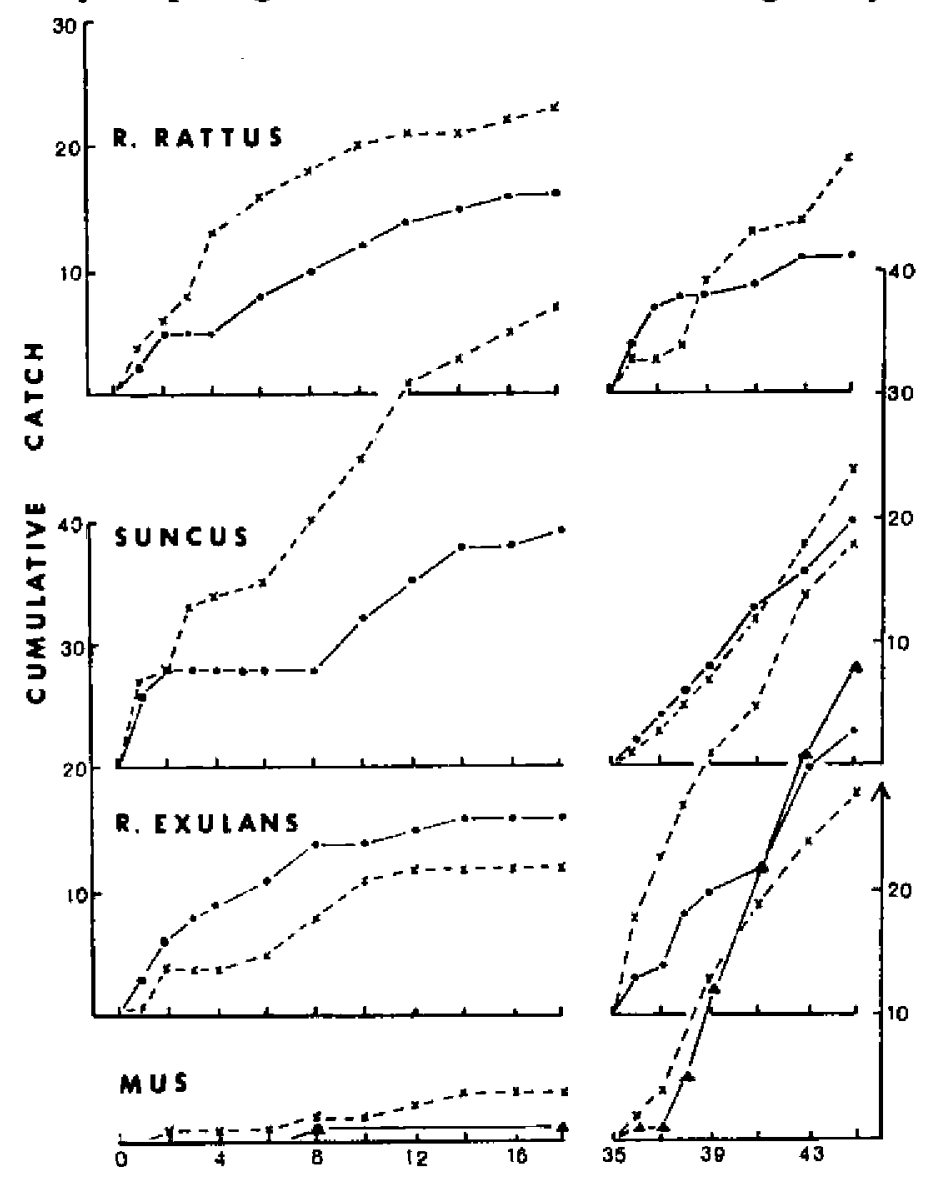

Fig. 5. Patterns of cumulative catch on inner (I-III, ) and outer (IV, $X$ ) squares of $S M$ IV grid $R S A_{1}$, . A severe typhoon hit Guam on the 20th day of trapping, resulting in a gap in the records for the untended traps. Traps were reset on what would have been the 35th day of trapping.

assumption of equal foraging time holds, this argument is not acceptable. As a first approximation, whether or not a member of any species is caught on day-one is a function of $r$ relative to trap spacing times the density of the species - if traps are set appropriately ( $\mathrm{B}$ a r behen $\mathbf{n}$, 1973). 


\section{INVASION}

From the viewpoint of an $S M$ grid, I define invasion as the penetration of the inner squares by animals originally unexposed to the grid. The contention that some animals with large ranges centered outside the grid are caught on the inner squares (e.g. S mith et al., 1971) is probably correct, but this should have no serious bearing on the results - some animals from the inner square are probably caught on $\omega$. I assume that

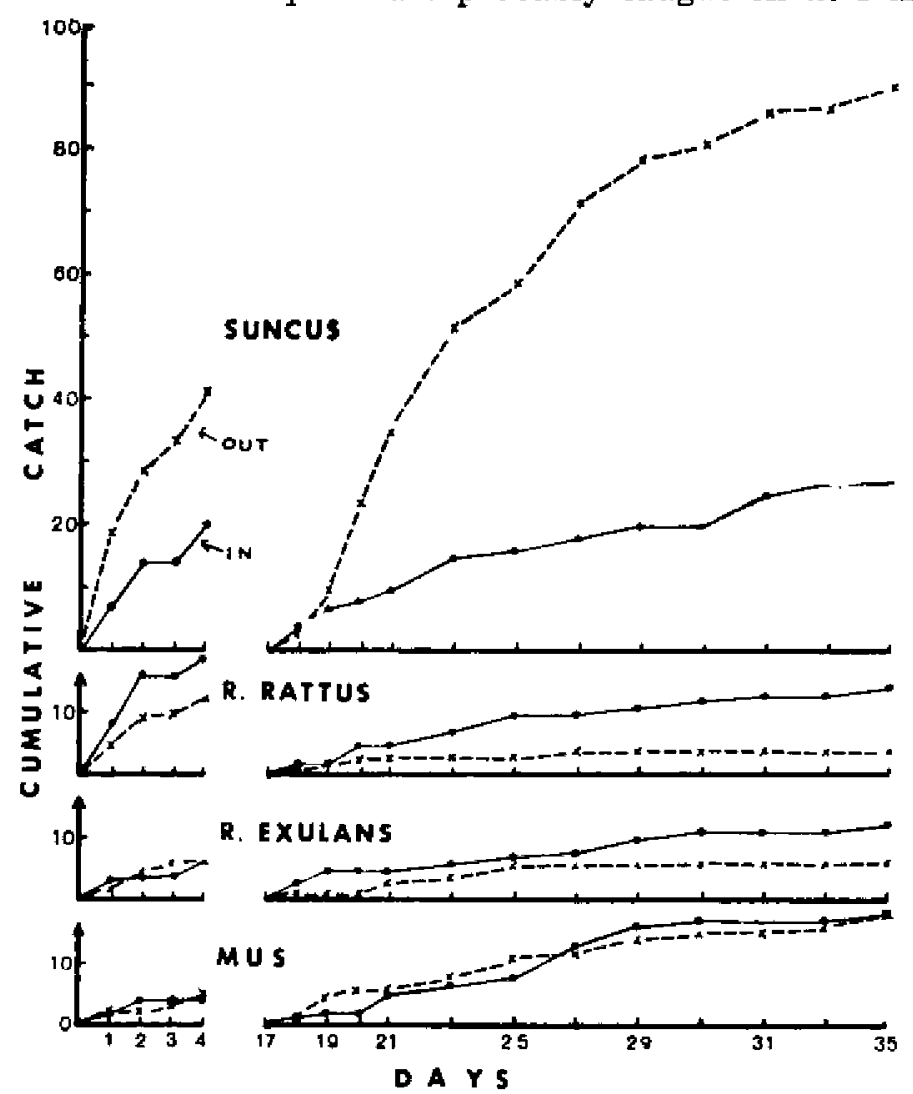

F'ig. 6. Patterns of cumulative catch on inner (.) and outer (X) squares of $S M$ IV grid RSB. Traps were lifted after the first four days and reset on what would have been the 17th day to mimic the gap caused by the typhoon in Fig. 5.

animals are most likely to be caught by traps nearest the center of their ranges and this may not prove true when behavior is influenced by removal trapping. Since $\omega$ seems to provide a good filter for animals with expanding ranges, I assume that invaders are animals that either do not have a home range (transients) or that have abandoned their ranges in response to the "vacuum\&. Without the benefit of marked animals 
whose ranges were known prior to removal trapping, I can only make inferences from observed patterns of capture.

With the probable exception of those $R$. rattus populations that apparently have large home ranges, I have no evidence that invasion of the inner square is of frequent occurrence during short-term trapping. Trapping for longer periods of time may be expected to induce invasion. Variations in the process have been observed within and between species as induced by removal trapping and, by chance, by the disruptive effects

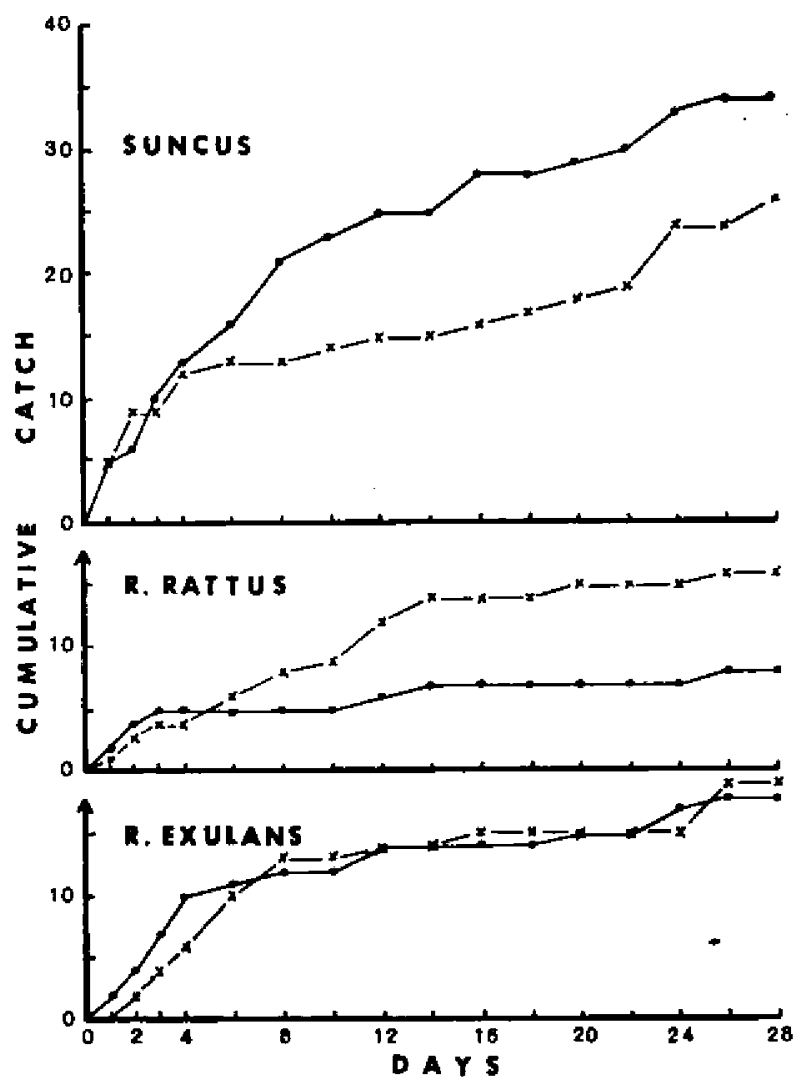

Fig. 7. Pattern of cumulative catch on inner (.) and outer $(X)$ squares of $S M$ IV grid RSA.

of a severe typhoon. All results from the long-term trapping of $S M$ IV grids on Guam are presented below.

$R S A_{1,2}$. This grid was set on 22 October 1962 with the intention of trapping it for 30 days. Results for the first 18 days (Fig. 5) provided estimates of $5 R$. rattus and 8 Suncus on the inner squares. The outer square provided a barrier to invasion until the sixth day for $R$. rattus and the tenth day for Suncus. $R$. exulans apparently had a very small 
range size but an estimate of from ten to 14 animals on the inner square is reasonable. Some invasion was apparent, possibly on day- 6 but more probably on day-8. Mus appeared to be absent on the inner squares and at low densities (possibly 1/ha) around the periphery of the grid.

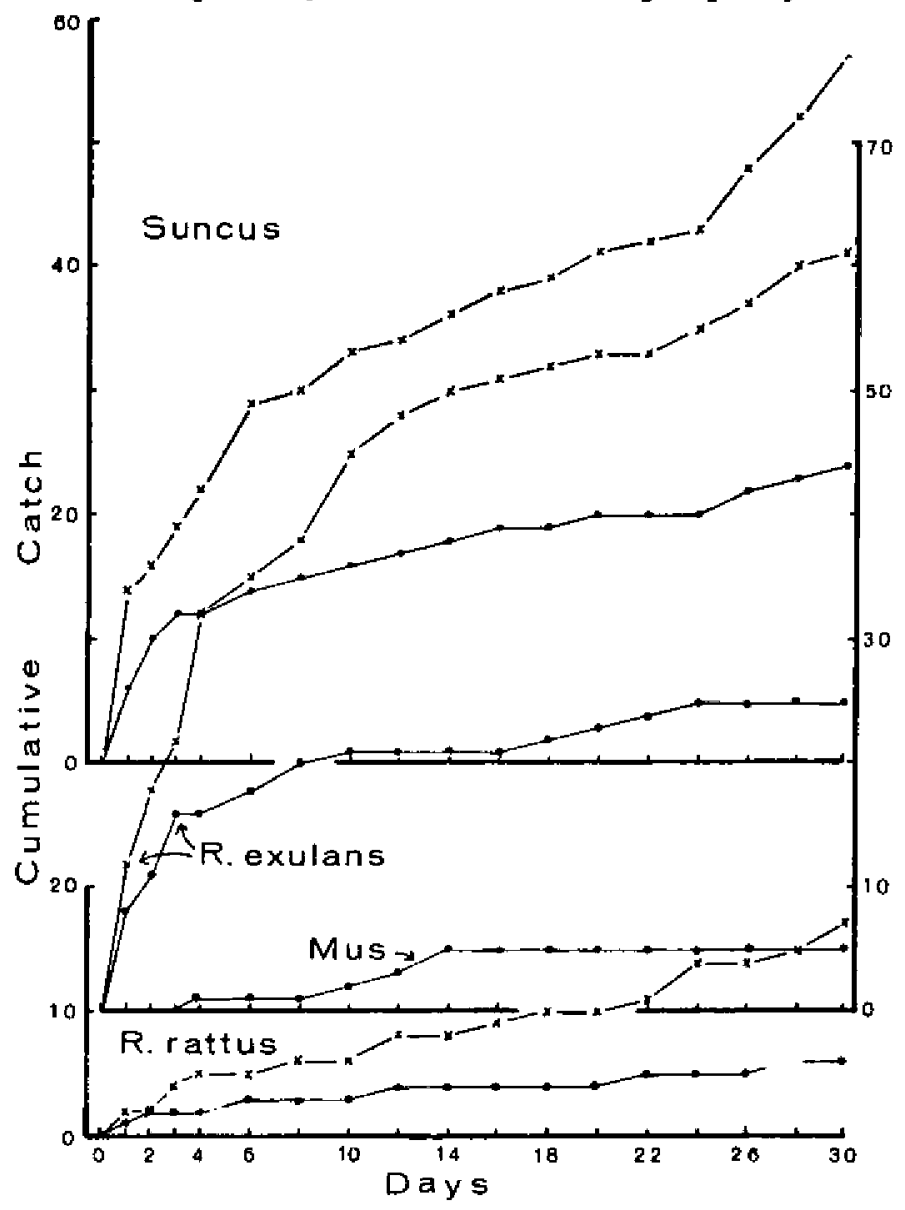

Fig. 8. Patterns of cumulative catch on inner $(\cdot)$ and outer $(X)$ squares of $S M$ IV grid $R S C_{1}$. No Mus were caught on the outer square.

A severe typhoon (Karen) hit Guam on 11-12 November, forcing the temporary abandonment of the grid. On 26 November the traps were re-set and short-term trapping provided an estimate of $10 \mathrm{R}$. rattus/ha (Fig. 5). The other three species however, appeared to pour incessantly into the grid as trapping proceeded, with $\omega$ acting as a partial filter for $R$. exulans. The slight lag in catching $M u s$ was probably caused by the fact that most of the traps had become rusty and insensitive. They were ciled on the second day and the catch of $61 \mathrm{Mus}$ over the next eight 
days provided a startling contrast to the catch of five during the first 18 days. The population of the three smaller species appeared to be totally disorganized with individuals wandering randomly over wide areas. At this point, the possible effects of the destruction of vegetation could not be separated from the possible consequences of long-term trapping. It was only obvious that $M u$ s and, to a somewhat lesser extent, $R$. exulans, had invaded the grid from relatively wide areas. The variability in the density of Mus in surrounding areas was unknown but the possibility of drawing most of the mice from an area of 20 tha seemed incredible.

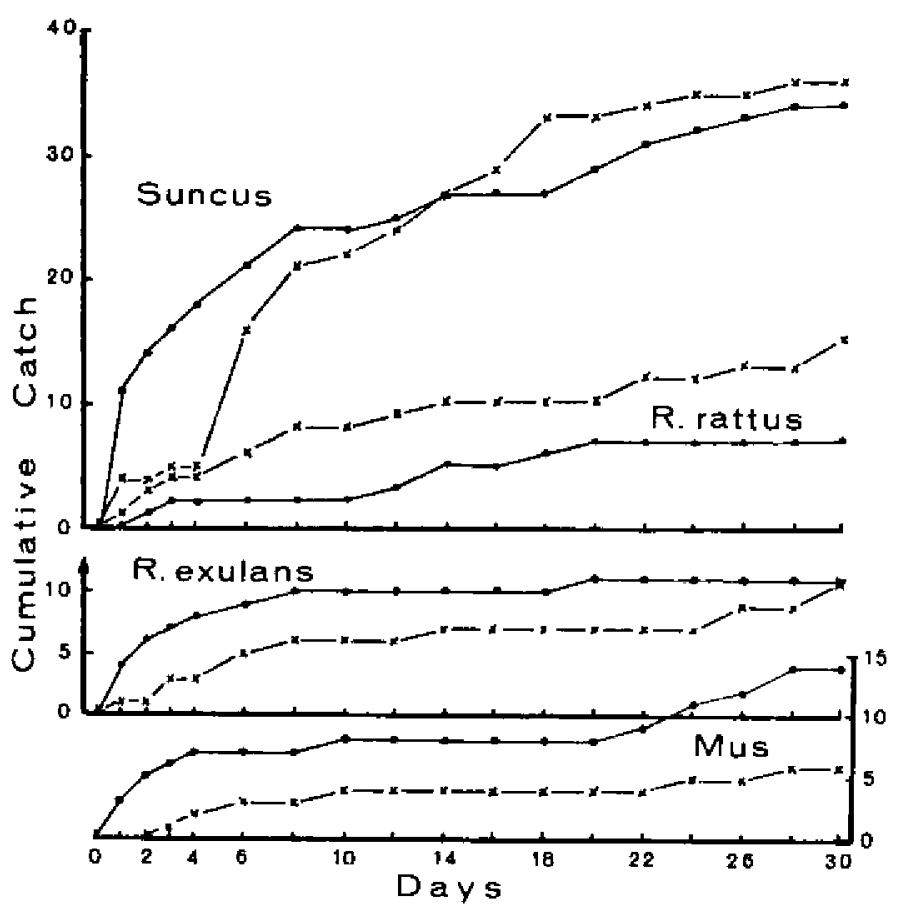

Fig. 9. Pattern of cumulative catch on inner $(\cdot)$ and outer $(X)$ squares for $S M$ IV grid $R S C_{q}$.

RSB. An attempt to repeat the pattern observed at $R S A$ was made in a similar area $300 \mathrm{~m}$ away. An SM IV grid was set on 3 December 1962 and run for four days (Fig. 6). While we cannot be certain the after effects of the typhoon were still influencing these populations, the capture sequences for Suncus and $R$. rattus on the inner square were somewhat deviant - a slight lag was apparent on day-1 and some invasion may have occurred on day-4. Shrews appeared to have an exceptionally large range while that for $R$. rattus was smaller. Results for $R$. exulans and Mus seemed reliable for such low densities. 
The traps were lifted after the four-day period and reset on 18 December to mimic the gap in trapping caused by the typhoon. The subsequent patterns of capture (Fig. 6) were much less dramatic than those observed at $R S A$ and new density estimates for Suncus and $R$. exulans seemed to be reliable. Suncus was sattracted « to the grid in large numbers but roughly $70 \%$ were intercepted by $\omega$. $R$. rattus penetrated $\omega$ freely while the effects of the barrier varied for R. exulans, apparently being effective for days- 1 through 8 and ineffective thereafter. Assuming the first two Mus caught on the inner squares represented the total population, invasion was extensive.

$R S A-3$. This grid was retrapped on 21 October 1963 (Fig. 7). In contrast to previous experience, Suncus seemed to invade freely while the $\omega$ barrier was effective for $R$. rattus. A lag in capturing $R$. exulans coupled with a small range size suggests that the catch through day-10 was a consequence of expansion from the inside rather than invasion from the outside. Mus was rare or absent.

$R S C-1$. This grid was separated from $R S A$ by a distance of $45 \mathrm{~m}$ and an unimproved road. Penetration of the inner square was greatly reduced by $\omega$ 'for' the three larger species (Fig. 8). No mice were caught on $\omega$ and one can only conclude that their density was very low.

RSC-2. Shrews apparently had very small ranges and invasion cannot be distinguished clearly from home range expansion (Fig. 9). Invasion by Suncus and $R$. rattus was apparent beginning on day-12 while Mus invaded on day- 22 .

The several patterns observed above make it clear that we cannot make sound predictions concerning the barrier effect of $\omega$, although chance has cast most of the aberrant results from short-term trapping into these long-term samples (See 3, VIII below). Long-term trapping induces movement toward the grid and the relative effectiveness of $\omega$ in intercepting invaders appears to be more related to the state of each population than to the species. Where ranges are small, delayed expansion cannot be clearly distinguished from invasion during short-term trapping but it appears that Suncus may sometimes invade when its ranges are small while the opposite is true for $R$, rattus. The consequences of these patterns to the estimation of density will be discussed below.

\section{ESTIMATING HOME RANGE RADIUS (r)}

1. Background Procedures and Problems

Two methods have been suggested for estimating $r$ from the edge effect. Hansson (1969) proposed the equation $N_{b} / b^{2}=N_{a}\left(a^{2}+4 a r+\pi r^{2}\right)$ 
for determining the average range of movement $(r)$, where $N_{b}$ is the population estimated on the inner squares; $N_{a}$ is the population estimated from the whole sampling area; $b$ is the side length of the inner square plus one-half the distance to the next trap; and $a$ is the side length of the sampling area (i.e. $(\omega)$. Smith, Gentry \& Golley (1969) and $\mathrm{S} \mathrm{m}$ ith, et al. (1971) accumulate trap success ( $P_{e}$ in their terminology) for squares from $\omega$ inwards and fit straight lines to the generated slopes: The intercept between the zone of high, decreasing TS and the zone of Iow, constant $T S$ is estimated as $r$. Both of these methods have some intrinsic weaknesses.

When $R C_{\omega}$ is either negative, zero, or even very low relative to $R C_{I}$, behavioral changes have occurred after day-1. I interpret these changes, in general, to be an expansion of range size for the small mammals of Guam and, as Hansson acknowledged, his method then becomes inappropriate since both $r$ and $N_{a}$ are changing with time. As indicated in the above theoretical section (II, 2), even if behavior does not change during the course of trapping, estimating $N_{a}$ from $C_{1}+C_{w}$ is subject to error if the probability of capture decreases with distance from the grid.

The logic of transferring the edge effect inwards ( $\mathrm{S} \mathrm{m}$ i th et al., 1969, $1971)$ is evasive but the validity of the procedure is easily tested against theoretical models that match their criteria. Whether one assumes either a uniform use of space (Fig. 1) or a pattern of movement that limits the edge effect to $\omega$, transferring the average edge effect inwards produces a smooth curve that can be divided into two straight segments only by rather arbitrary methods. Since S mith et al. (1971:117) indicate that "...three points are minimal for the calculation of the regression equation...*, $\hat{r}$ will approximate $30 \mathrm{~m}$ regardless of any true value greater than $10 \mathrm{~m}$. The value estimated by this graphical method is merely an artifact and is not "...equivalent to the $r$ of $\mathrm{H}$ an S S on (1969) «. That $\mathrm{Smith}$ et al. (1971:Fig. 8) observed a good fit to a straight line was due to a relatively large catch on (1)-1. The reason for this is not evident but it seems unrealistic to attempt a measurement of $r$ for a combination of three species after 18 days of trapping. My estimate of this original catch indicates that no edge effect was observed on $\omega-2$, despite appearances generated by their procedure.

\section{A Recommended Procedure}

I have modified Hansson's method by assuming that $C_{\omega}$ and $C_{I}$ are proportional to the numbers of animals exposed to traps on day-1. In practice, small samples are subject to random variation and I conventionally use the averages between $C_{1}$ and $C_{1,2}$ as the estimator. This proce- 
dure tends to overestimate small ranges but otherwise gives more reliable results. For an $S M$ IV grid, the $H R$ Index $=1.286 C_{\omega} / C_{r}$, since the ratio of inner:outer traps is 9:7. For $S M V$ through $S M$ VIII grids, the correction factor $(f)$ for converting $C_{\omega} / C_{I}$ to relative TS is $1.778(16 / 9)$, $2.273(25 / 11), 2.769(36 / 13)$, and $3.267(48 / 15)$, respectively.

The value of $r$ corresponding to the $H R$ Index>1.0 can be read directly from Fig. 10 for $S M$ IV and SM VIII grids. The two curves diverge as $r$ increases because of a corner effect. Values for intermediate $S M$ grids can

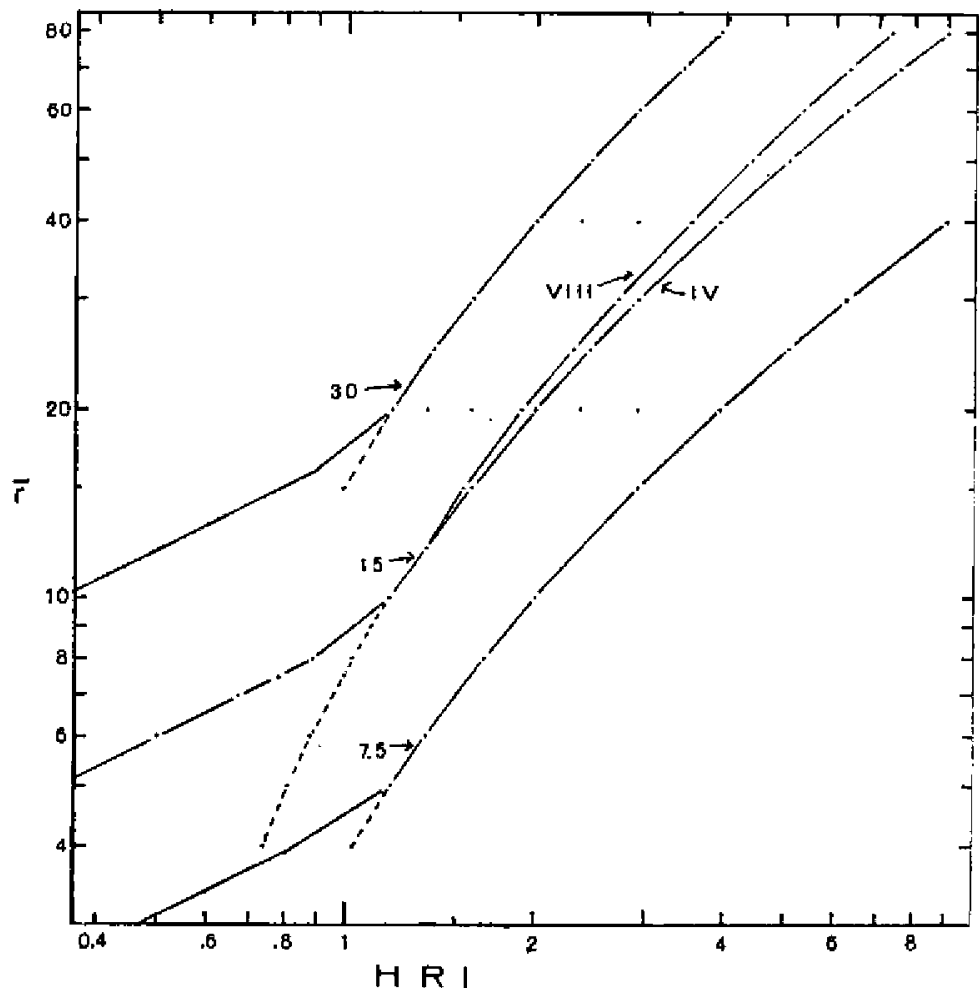

Fig. 10. The mean home range radius $(r)$ of a population as estimated from the home range index ( $H R I=$ relative trap success for the outer grid square on day-1; see text). Curves are for trap spacings of $7.5,15$ and $30 \mathrm{~m}$ on grids having four (IV) squares (64 trap stations). Curves for trap spacing of 10,12.5, and $25 \mathrm{~m}$ may be interpolated from the anchor points placed at $r=20$ and $40 \mathrm{~m}$. For grids with more than four squares, $\hat{r}$ should be increased in proportion to that indicated $f$ an $S M$ VIII grid. Dashed lines indicate relationships derived from Hanss on's (1969) equation below the point where all animals are exposed to traps. Estimates of $\hat{r}$ for this region were made by methods and assumptions described in the text. 
be interpolated. Theoretically, $r$ cannot be estimated when it falls below $10 \mathrm{~m}$ on a $S M$ grid, despite the fact that Hansson's equation continues to generate expected values; some animals inside the grid are not exposed to traps. Yet, observations of a negative edge effect $(H R I<1.0)$ were common in Guam (Fig. 4). Assuming that $r$ expands to at least $10 \mathrm{~m}$ on the inner squares but remains unchanged on $\omega$ the original $r$ can be calculated directly (see 3.IV above). In fact, some animals on the inner squares may remain unexposed and some expansion may occur on $\omega$, leading to an overestimate of the initial $r$. Whether or not $r$ can actually be reduced to $7 \mathrm{~m}$ or less for Suncus and $4 \mathrm{~m}$ for $R$. exulans on Guam would be very difficult to determine reliably, but evidence for values below $r=7.5 \mathrm{~m}$ is strong.

A trap spacing $(d)$ of $15 \mathrm{~m}$ is too great for ranges averaging less than $10 \mathrm{~m}$ in radius and efficiency may be lost where populations are characteristically sparce with ranges generally exceeding $r=30 \mathrm{~m}$. A station interval of $15 \mathrm{~m}$ seems to be a good initial choice for an unfamiliar community, however when experience proves that a change in $d$, is desirable, $r$ can be estimated by intercalating curves through the anchor points provided on Fig. 10 for SS IV and SL IV grids.

\section{Confirmation}

A single test of the accuracy of deriving $\hat{r}$ from removal trapping is provided by a comparison with results obtained by live trapping. A grid of 88 stations ( $10 \times 10$ minus 3 stations at each corner) was established with a $22 \mathrm{~m}$ spacing. One large $(10 \times 10 \times 30 \mathrm{~cm})$ and one small $(8 \times 8 \times 23 \mathrm{~cm})$ wire mesh live trap baited with coconut were placed at each station and were checked just before sunset and again in the morning. In the four days of each trapping session, traps at each station were moved progressively around the corners of an $11 \mathrm{~m}$ square. The area was trapped during August, September, and October 1962. The November session was missed because of Typhoon Karen, and a four-week interval was resumed for December, January, and February. Animals were marked individually by toe-clipping and released immediately at the place of capture.

The simplest index of home range size is the distance moved between successive recaptures and mean values of this measure (av. D., B r a nt, 1962) are appropriate here for comparative purposes (Table 6). In general, differences in range size related to sex are greater than those related to species. Considering the fact that instantaneous estimates of range size from $S M$ IV grids produced many estimates of $\mathrm{r}<10 \mathrm{~m}$ for all four 
species, the similarity in the large av. $D$ among the four species on this grid is striking.

After the last live trapping, an SM IV grid of snap traps was laid in the middle of the live trap area. The estimates of $r$ thus produced for the three large species (Table 6) are slightly less than those observed for females and $25-30 \%$ lower than the averages for both sexes. While this discrepancy might be considered substantial, there are several reasons why a difference in the observed direction would be anticipated. Shifting live traps each day greatly reduced the chance of recording a distance of zero. Only 16 of 575 successive captures were at the same station secause most of the time the same station was not available. Movements

Table 6

Average distances (av. D., in meters) moved between successive captures and an estimate of mean home range radius $(\hat{r})$ derived from two days of snap trapping $\left(C_{1,2}\right)$ four weeks after the final live trapping.

\begin{tabular}{|c|c|c|c|c|c|c|}
\hline \multirow[b]{2}{*}{ Species } & \multicolumn{2}{|c|}{ Males } & \multicolumn{2}{|c|}{ Females } & \multicolumn{2}{|c|}{ Total Population } \\
\hline & IN obs. & av. D. & N. obs. & av. D. & $C_{1,2}$ & $\hat{r}$ \\
\hline Suncus & 113 & 32 & 106 & 24 & 29 & 22 \\
\hline R. rattus & 73 & 34 & 71 & 28 & 39 & 26 \\
\hline R. exulans & 97 & 30 & 62 & 23 & 20 & 20 \\
\hline Mus & 25 & 33 & 28 & 27 & 3 & 7 \\
\hline
\end{tabular}

made within trapping periods were compared with those made between periods and it was observed that male rats of both species especially made longer movements between periods. Some shifting and expansion of range size is to be expected over an eight-month period and an illusion of a larger range size would be generated. Animals marked as juveniles may either disperse or expand their ranges as they mature between trapping periods, whereas an instantaneous estimate includes some animals that have not left the home nest area. Finally Pear s on (1960), and $S$ heppe (1967) have provided evidence that the process of live trapping may alter patterns of movement. Thus, long-term live trapping would be expected to produce higher estimates of range size.

On the more positive side of the comparison, both methods are in agreement that the larger species have similar range sizes, and all were well above the average for Guam (Table 3 and Fig. 10). The fact that estimates for $R$. rattus were the largest and those for $R$. exulans were the smallest in both cases may be fortuitous. The estimate of $r$ for Mus should be ignored because of the very small sample size. 


\section{Implications of the Observations on Range Size}

The apparent absence of edge effect on $\omega-1$ could have resulted from pooling results in Table 2, since the average $\vec{r}$ is slightly less than $15 \mathrm{~m}$ for the three larger species and no effect on $\omega-1$ is expected (Fig. 1). For the six grids with the largest estimate of $r$ for Suncus $(24-35 \mathrm{~m})$, the catch on $\omega-1$ relative to I and II on day-1 was slightly Iower than expected. For the remaining grids, the agreement was even more precise. The minor deviations observed in Table 2, therefore, are the result of events after day-1 and again suggest some invasion to $\omega-1$ when initial ranges are relatively small.

For $R$, rattus with large ranges, again there is a slight deficit on $(0-1$ on day-1. An invasion to the center of the grid apparently occurs on day-2, if the small numbers are reliable. In any event, there is no evidence that animals with large ranges produce an edge effect on $\omega-1$ on day-1. The results are consistent with the concept that animals make greater use of the area nearest the centers of their ranges unless perturbed by removal trapping. If patterns of movement approximate the bivariate normal distribution ( $\mathrm{Ca}$ a h o u \& $\mathrm{C}$ a s by, 1958), then the concept of $r$ should be modified accordingly.

While no great reliance can be placed on $\hat{r}$ from a single grid, evidence from pooled samples (Fig. 4) indicates that $\hat{r}$ varied from 7 to $30 \mathrm{~m}$ for both Suncus and for $R$. rattus, and 4 to $20 \mathrm{~m}$ for $R$. exulans at the population level. Whatever the reasons for this substantial variation, if home range size is the criterion used for assessing relative dominance ( $\mathrm{C}$ a $\mathrm{lh}$ ou n, 1964), then it appears that the hierarchy is not stable. My previous characterization of community organization on Guam (B a r be$h$ e $n, 1969$ ) was based on the average condition and was an oversimplication of the situation. This theme will be developed elsewhere but is appropriate to indicate that Calhoun's general thesis is not discredited by such variable results.

\section{ESTIMATING DENSITY (D)}

The above analyses illustrate several relevant principles in estimating densities. As noted by many authors, if a positive edge effect is observed, the area from which animals are drawn exceeds that covered by an $S M$ grid plus a border of $7.5 \mathrm{~m}$. Few workers appreciate the alternative: If the initial edge effect is either zero or negative, serious bias is possible regardless of the short-term rates of capture. In addition, variation in behavioral responses both within and among species for which the 
trapping device is appropriate reduces predictability. These points deserve further elaboration.

\section{Variability}

Interspecific variability in trap response is widely recognized and, where the reasons for the deviations are known, methods can be improved experimentally ( $\mathrm{B}$ a r behe $n, 1973 ; 1974$ ). Most of the variation in trap response observed in Guam can be attributed to intraspecific differences in initial range size and the consequence is largely limited to the edge effect. Aberrant results have been observed on several occasions, however, and such variation requires the use of some subjective judgement in estimating $D$. A more important consequence is that an intensive study of a single population, however elegant, has limited value for testing generalizations. Assessing the filtering efficiency of $\omega$ must be done systematically and, where a pattern such as that found for $R$. rattus (Fig. 4) is found, a correction for the bias is possible.

\section{Positive Edge Effect}

The common existence of a positive edge effect is now widely recognized (e.g., Chelkowska \& Ry szkowski, 1967) and, where this is observed on their first day, the probable cause is that relatively more animals are exposed to the outer square when $r>0.67 \mathrm{~d}$. In estimating density, two general solutions to the problem are possible. One is to discount the catch on the outer square(s) (e.g., B uch a l cz y k \& Pucek, 1968; Pelikán, 1969) and the other is to attempt an estimate of the area from which the total catch is drawn - the area of effect (e.g. Smith et al., 1971). Both procedures contain some inherent weaknesses and a comparison is in order; there are no alternatives.

If $\omega$ generally acts as an effective filter, then the simplest procedure in estimating density is to discount the catch on $\omega$; both $\hat{N}$ and $A$ (area) can be determined from the inner squares. This procedure was generally appropriate in Guam with $S M$ IV grids but, in practice, some workers (e.g. A u la k, 1967) have reported edge effects on $\omega-1$ and $\omega-2$ for $S M$ VIII grids. In such cases, Pelikan's recommendation for eliminating the edge effect seems appropriate but, to refine our methods, it would be useful to gain a clearer understanding of the cause of the problem.

Possible reasons for an apparent edge effect beyond $\omega$ include normal patterns of movement that reduce the filter effect ( $B$ a $r$ beh en $n, 1974$ ), habitat patchiness, and prebaiting the grid ( $\mathrm{B}$ a bin n k a \& B o ck, 1969). Regarding the last possibility, the experiments of $\mathrm{Pelika} n, Z \mathrm{Z} \mathrm{jda}$ \& Holišova (1972) show rather convicingly that the edge effect on day-1 for Clethrionomys glareolus did not differ between prebaited and 
untreated grids. A pronounced edge effect on prebaited grids was subsequently produced by animals that had not been marked by the dyed pre-bait. Since dye-marked animals on the prebaited grids were removed at a very high rate $(\hat{p}=0,7)$ in contrast to animals on untreated grids $(\hat{p}=0.23)$, it seems likely that the strong edge effect that developed on prebaited grids after day-1 was caused by the sudden "vacuum $\%$. The edge effect was apparently limited to $\omega$ in this case but it is possible that more extended prebaiting could produce qualitatively different results. Additional analyses seem necessary but, in any event, the inner square method seems theoretically sound for many situations. For animals that make extensive use of runways, however, the presence of a positive edge effect on day-1 does not provide assurance that most of the animals within the grid are exposed to the traps (B a r b e he n n, 1974).

Several workers have attempted to determine the source of animals caught on a grid by employing a variety of methods to mark animals prior to removal trapping. At this point, however, I will limit discussion to estimating the area of effect from records of unmarked animals. Calculating the average range of movement ( $\mathrm{Hanss}$ on, 1969) is inappropriate because the reasoning would be circular. The same would be true for regressing the cumulative edge effect on the outer squares (Smith, Gentry \& Golley, 1968), even if the method were valid. The only direct method proposed for unmarked animals is to deploy lines of traps oriented radially to the grid. The purpose of these assessment lines is to measure the zones of complete, partial, and zero removal of animals created by the grid ( $\mathrm{Sm}$ i th, et al., 1971).

Using extended trapping and assessment lines, $\mathrm{S} \mathrm{m}$ it $\mathrm{h}$ et al. (1971) have challenged the general validity of the inner square method. They argue that the results from the inner square are unreliable and represent an overestimation of $D$ caused by the extensive penetration of animals with large, shifting ranges. Their argument hinges on critical assumptions and faulty procedures.

They assume that an 18-day catch represents the total, population from both the grid and the area of effect and, thus, has no confidence limits. The tempo of events, however, is not predictable either in their environment (Gentry, Golley \& Smith, 1971) or in Guam (Figs. 5-9). Any assumption that the area of effect is the same for each of several species at any predetermined point in time is untenable.

Confidence Iimits for the area of effect were estimated without regard for the limit set by the interval between assessment traps. If the area of effect is determined by accumulating captures beginning at the grid 
instead of at the distal end of the lines, a discrepancy equal to the trap spacing is produced even if the results fit the model perfectly.

The above criticisms alone suffice to question the potential accuracy of assessment lines but their analysis also depends on an assumption of homogeniety in the dispersion of animals. While they report that the habitat appeared homogeneous, this was not measured. Even so, the small mammals could deviate and a simple $\chi^{2}$ test for homogeniety could be conducted by subdividing the grid into quarters and examining the catches by species and time. Unfortunately, this procedure will not detect radially symmetric heterogeneity or gradients and this is critical to the argument.

The observations of $\mathrm{Smith}$ et al. (1971: Fig. 9 and Table 1) suggest that the original density on the inner five squares was substantially higher than that on the rest of the grid (roughly $25: 17 /$ ha). They contend (1971:119) that marked invasion of the inner squares occurred on the first day of trapping. If confirmed, this would justify their doubts on the reliability of the method for their community. Unique observations are difficult to evaluate with proper perspective but, until additional studies are conducted, the parsimonious hypothesis is that they intuitively picked a "good place" to establish the grid.

$\mathrm{Sm}$ ith et al. (1971: 122) seem convinced that "Small mammals are much more mobile than previously recognized ( $F$ a us $t$ et al., 1971)...* and, since this factor is near the heart of their general rejection of the inner square method, the basis for their belief might be reviewed. F a ust, Sm ith \& Wray (1971), using mark and recapture methods on an exceptionally large area for an exceptionally long period of time, reported exceptionally long movements between recaptures for the three species considered by $\mathrm{S} \mathrm{m}$ it h el al. (1971). Total densities were generally low $(<10 /$ ha) and the conclusions may be reasonable. However, $48+$ days after completion of the live trapping study, all marked animals apparently had disappeared from the large study area (Gentry, Smith \& $B$ e y e r s, 1971). This is one of the highest rates of disappearance in the annals of mammalogy, and the marked population was apparently replaced by unmarked individuals. From this and other details, it seems apparent that Faust et al. (1971) were dealing with a highly unstable community containing a very high proportion of transients.

The above observations provide another meaningful lesson: Small mammal communities may exhibit very deviant properties without the obvious presence of storms, fires, or human disturbances. It is rather pointless, however, to propose an obvious deviant as a norm.

An $S M$ grid with conventional traps set on the ground surface is unreliable for estimating densities of many species. By treating the small 
mammal community as a unit, however, $\mathrm{S} \mathrm{m}$ ith et al. (1971) failed to demonstrate that reliability was enhanced for any one of their three common species by using assessment lines. The reliability of the inner square method may be enhanced for some species by modifying methods appropriately ( $\mathrm{B}$ a $\mathrm{r}$ behen $n, 1973$ ). Without a more convincing proof that such procedures are both generally faulty and not correctable, I see no point in intentionally inducing an invasion by extended trapping and then attempting to measure the area of effect from a handful of animals taken on assessment lines.

\section{Inverse and Zero Edge Effect}

The problems that arise in estimating density when no positive edge effect is observed on day-1 are more subtle. If a positive edge effect on day-1 is generated by animals with $r$ greater than $10 \mathrm{~m}$ on an $S M$ grid, the absence of an edge effect indicates that $r$ is less than $10 \mathrm{~m}$ (assuming a homogeneous habitat). This being the case, we can, a priori, assume that some fraction of the animals resident on the inner square are not exposed to traps on day-1. If home ranges expand gradually, either a low rate of capture or an increase in catch with time will alert the investigator to the fact that the trap spacing was too great. One practical remedy is to continue trapping, possibly with a shifting of traps, until the daily catch declines. Assuming no invasion is induced, at least an estimate of minimum density is provided by the total catch and this will be more accurate than a guess made before the catch declines sharply.

A more insidious problem arises if a high rate of capture is obtained en the inner squares during short term trapping, and this situation may he typical following prebaiting. I have indicated that $S M$ grids on Guam were generally adequate to expose most individuals on the inner square hecause animals whose ranges are compressed generally appear to expand very rapidly when the pressure is released by removal trapping. On the other hand, at station spacings of 30 and $43 \mathrm{~m}$ (Table 4), relatively high rates of capture were often observed for Suncus and $R$. rattus during short-term trapping even though large numbers of animals were not originally exposed to the traps. If range size is relatively large initially, expansion occurs more slowly and gives no evidence that traps are too widely spaced. A trap spacing of $43 \mathrm{~m}$ is obviously too large for Suncus and Rattus; the question is, is the $S M$ spacing of $15 \mathrm{~m}$ generally too large for other taxa? In general, if no positive edge effect is observed on day-1, one should suspect that $N$ has been underestimated regardless of the pattern of capture. 
Observations in Guam were that $R C_{\omega}$ was generally low when $\dot{r}$ was small. In consequence, one cannot estimate the area of effect from the catch on the outer square and adding $C_{\omega}$ to $C_{I}$ cannot produce a valid estimate for the grid plus the area of effect. While other species may not fit the patterns observed on Guam, my general recommendation is that the catch on $\omega$ should never be used directly in estimating $D$, whether or not an edge effect is observed. I cannot conceive of a situation where incorporating the catch on $\omega$ would increase accuracy in estimating $D$, although the adjunct information is certainly useful in interpreting initial range size and behavioral changes.

\section{CONFIDENCE LIMITS AND RELIABILITY}

$\mathrm{S} \mathrm{m}$ ith et al. (1971:105) stressed the importance of sreliable density estimates", but "reliability " must be defined. Smith et al. would judge reliability by how good the sequence of captures fits the model in each case, by estimates of confidence limits, and by sample size. Perhaps they would employ other criteria as well but these three are inadequate since we must also distinguish between "precision « and »accuracy".

\section{Goodness of Fit}

In addition to behavioral problems that may render the assumptions invalid, S mith et al. (1971) indicate that $\mathrm{H}$ a y $\mathrm{m}$ e's (1949a) method is statistically weak because the coefficient of correlation is seldom significant in short term trapping. This may be true, but a constant probability of capture is an assumption of the method and a non-significant fit alone does not invalidate the assumption. Confidence in the assumption, which is also essential to the maximum likelihood method ( $\mathrm{Z}$ i p p i n, 1956), comes omly from extensive testing. For instance, the assumption is generally valid for Suncus on the inner squares but is often invalid on the outer square (Figs. $3 \& 4$ ). Invasions induced by extended trapping also invalidate the assumption.

If it seems necessary to calculate the coefficient of correlation for Hayne's method, then the problem that "... the $X$ variable is accumulated captures and thus not strictly a random variable... $\mathrm{Smith}$ et al., 1971:122) can be avoided by the alternative procedure of plotting the logarithm of the daily catch against time. Graphically, the number of uncaught animals can be estimated by projecting the fitted line for an appropriate number of days, depending on the slope. (However, see Zip pin, 1956:174). 
2. Confidence Limits for $\hat{N}$

For a single grid, confidence limits for $\hat{N}$ provide a measure of precision. Confidence limits suggesting that $\hat{N}$ may be less than total already removed ( $\mathrm{S} \mathrm{mith}$ et al. 1971: Fig. 7; Zi p p in, 1958: Eq. 2), however, are illogical. The underlying rationale of both $\mathrm{H}$ a y $\mathrm{n}$ e's (1949a) and $\mathrm{Z}$ i p p i n's $(1956,1958)$, methods is that, if the probability of capture remains unchanged, the sequence of capture for the remaining animals is predictable. Hayne graphically estimates $N$ directly while Zippin's multinomial method first estimates the proportion already removed $\left(1-q^{k}\right)$, where $k$ is the number of trapping days. In both cases, there is no error associated with the number already removed $(T)$ and the error of the estimate should be concerned only with how many animals remain $(\hat{N}-T)$. Therefore, confidence limits for $\hat{N}$ are a function of $S E\left(1-\hat{q}^{\mathrm{k}}\right)$, which is a function of $S E(\hat{p})$, for which a simple equation is available $\left(\mathrm{Zi} \mathrm{p} \mathrm{pin,} \mathrm{1958;} \mathrm{Eq.} \mathrm{3):} S E(\hat{p})^{2}=\mathrm{T}(\hat{p q})^{2} / T^{2} \hat{q}-\hat{N}(\hat{N}-T)(k \hat{p})^{2}\right.$.

$\mathrm{Z}$ i p p in $(1958: 87)$ indicated that his $S E(\hat{N})$ provides $90 \%$ confidence limits for sample sizes between 50 and 200. Confidence limits derived from $S E(\hat{p})$ are strongly skewed (since $\hat{N}=T /\left(1-\hat{q}^{\mathrm{k}}\right), \hat{N}$ cannot be less than $T$ ) and the upper limits are substantially larger than those derived from Zippin's $S E(\hat{N})$ for small samples. Fig. 11 provides a rapid method of estimating confidence limits for the special case of $k=4$. Where either $\hat{p}$ or $T$ is small, the upper limit is discouragingly large. (See $\mathrm{Zi} \mathrm{p} \mathrm{p} \mathrm{in,}$ 1956: Fig. 3). For $T>100$ and $\hat{p}>0.3$, confidence limits calculated by the two methods are very similar.

\section{Consistency of $\hat{p}$}

A more reliable measure of a method's precision is its ability to repeat results. For $S M$ grids, the variability of $\hat{p}$ under relatively uniform conditions is appropriate. From the inner squares of 19 SMIV grids having a total catch of five or more. Suncus, $p$ for Suncus ranged from 0.18 to 0.80 , with a mean $(\hat{p})$ of 0.454 and two standard errors $(S E)$ of 0.072 . These observed values for $\hat{p}$ fit a normal distribution and, on statistical grounds, three cases where $\hat{p}$ approximated zero could be 
rejected as abnormal. The total catch averaged 13.3 for the 19 normal samples and 9.0 for those rejected.

Similarly, for 16 grids, $\bar{p} \pm 2 S E(\bar{p})$ for $R$. rattus was $0.430 \pm 0.084$ and, for $R$. exulans on 13 grids, $0.433 \pm 0.100$. Again, estimates of $\hat{p}$ near zero for three grids (one for $R$. rattus, two for $R$. exulans) could be rejected.

The probability of capture on the inner squares appears to be independent of density for all three species and independent of home range size for Suncus and $R$. exulans (Fig. 4). While an observed range of $\hat{p}$ from 0.18 to 0.80 for Suncus may seem too great to be independent of other variables, such extremes are easily generated for my relatively

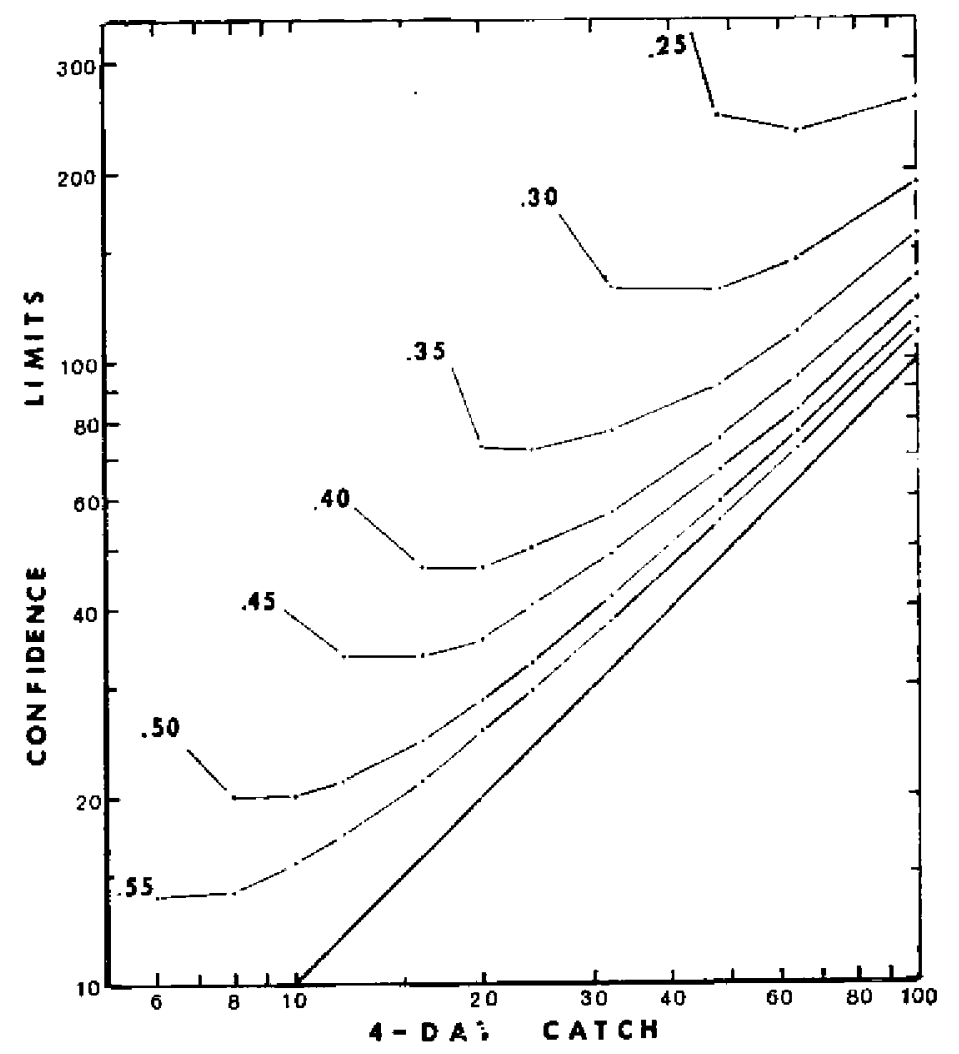

Fig. 11. Relationship between $T$ (the total catch for a 4-day period), the observed probability of capture $\hat{p}=0.25$ to 0.55$)$ and the $95 \%$ confidence limits for $\hat{N}$, The $J$-shaped curves indicate the upper limits. Except for very large T's at relatively low $\hat{p}$ 's, the lower limit approximates T. $\hat{N}=T /\left(1-q^{k}\right)$, where $q=1-\hat{p}$ and $k$ is the number of trapping days. Increasing $k$ will decrease the confidence intervals. 
small samples from the binomial distribution. Thus, unless $\hat{p}$ approximates zero, we can assume that $\bar{p}=0.454$ will provide the best estimate of $1-\hat{q}^{\mathrm{k}}$ for all samples and $\hat{N}=T / 0.91$. Confidence limits for $\hat{N}$ can be derived from $S E(\bar{p})$ and range from $T$ to $1.17 T$ for Suncus. To be conservative, however, when $\hat{p}$ falls below $\bar{p}-2 S E(\bar{p})$, the observed $\hat{p}$ should be used to estimate the upper confidence limit for $\dot{N}$.

\section{Accuracy and Bias}

Given a data base for any combination of species, habitat and method, it may be possible to demonstrate higher levels of precision from the consistency of the results. Good precision, however, does not necessarily mean that the results are accurate. If, for instance, some large fraction of the population is not exposed to the traps, small confidence limits for $\hat{N}$ are misleading if one wishes to estimate density.

For example, $56 R$. rattus were caught on the inner squares of an $S L_{43} V$ grid by day-6 (Table 4). The upper $95 \%$ confidence limit for the $\hat{N}$ of 59 was 65 , yet $100 R$. rattus were eventually caught. While some invasion was possible, most of the rats caught after day-6 were residents that had not been exposed to the traps initially. Had the trapping sites been prebaited, producing a higher rate of capture, confidence in the estimate would be higher but $D$ would still have been underestimated. Narrow confidence limits do not make an estimate reliable when the results are not accurate because of a bias in the method.

Lack of bias due to excessive trap spacing on $S M$ grids was demonstrated in Guam by shifting trap locations after two days of trapping on experimental grids. The same procedure indicated the presence of a bias on $S L_{30}$ grids. Other procedures (Fig. 4) suggested a bias in the catch of R. rattus related to home range size. Such testing can increase accuracy by using correction factors. The results thus become more reliable even though the precision of the correction factor is uncertain.

Had the pattern of capture for Mus in Guam (Table 5) not resembled that for the larger species, very few of the estimates could be considered reliable. As it now stands, accuracy in estimating the density of Mus with $S M$ IV grids was relatively poor because density was generally low and the trap spacing was often too great.

\section{Sample Size}

Characterizing density estimates derived from small numbers as "almost worthless" ( $\mathrm{S} \mathrm{m} \mathrm{ith} \mathrm{et} \mathrm{al.} \mathrm{1971:120)} \mathrm{is} \mathrm{inappropriate} \mathrm{as} \mathrm{a} \mathrm{genera-}$ 
lization. As an extreme example, the catch sequence of Suncus on the inner squares of one SM IV grid in Guam was 0-0-1-0, S mith et al. might claim that no estimate is possible but I am highly confident that density was on the order of $1 /$ ha because the general reliability of the method has been demonstrated. Only two shrews were caught on $\omega$. Since the next lowest $S M$ IV density estimate of Suncus in Guam was $6.8 /$ ha, the estimate of $1 /$ ha is of considerable biological importance. The estimate is "reliable" although it may not be "precise " because no confidence interval can be estimated. Had a catch $0-0-1-0$ been observed for Sorex cinereus using an SM IV grid in a Maryland forest, I would conclude only that the species was present and make no judgement concerning density. In this situation, the method is unreliable.

As a generalization, precision is a function of sample size and, from this consideration alone, precision should increase within the number of grid squares if homogeniety in the habitat is not sacrificed. Adding another square to my standard grids in Micronesia would have seriously limited the mumber of areas available for trapping and the advantages of larger samples must be balanced against other considerations.

A more subtle problem is introduced by Pelik á n's (1969) suggestion that the presence of an edge effect be evaluated by a $\chi^{2}$ test and that non-significant values be ignored in estimating density. This procedure makes the conclusion a function of sample size and as Pelikán (1969:60) noted, *...the edge effect can appear with varying intensity and, apparently, irrespective of population density...\&. One cannot assume that the effect is absent simply because small numbers preclude a statistical verification. In any event, I see no practical advantages for including the catch on $\omega$ in estimating density.

\section{Supplementary Proofs}

Once patterns of relationships have been determined, "supplementary proofs « ( $\mathrm{T}$ a $\mathrm{n}$ a $\mathrm{k}$ a 1966) can be employed to guide biological judgement where misplaced statistical rigor would render observations either salmost worthless s or not worth considering. If the outside: inside catches of Suncus on each of two $S M$ grids on day-1 were $7: 3$ and $3: 7$, respectively, there is mo need either to discard or to ignore the observations simply because the two ratios could be chance deviations from a zero edge effect, 4.4:5.6. A ratio of $7: 3$ implies a large home range $(\hat{r}=30 \mathrm{~m}$, Fig. 11), and, if so, the catch on the total grid should decline sharply with time (Figs. 3 and 4). A ratio of $3: 7$ suggests a small range $(\hat{r}=6 \mathrm{~m})$ and the catch on $\omega$ should remain constant or even increase. If these relationships 
are observed, we can be confident a difference in range size existed, although precision would be low.

Had Pelik á n's (1969) criterion been employed above and the edge effects rejected, $D$ might have been overestimated in both cases. As a more extreme example, for Mus with small ranges (Table 5), the mean density from the entire grid would appear to be 31/ha instead of the $3.7 /$ ha determined from the inner squares. The judgement of reliability comes from both experience and understanding. Once patterns of trap response have been discovered, subjectivity can be reduced without resorting to rather arbitrary methods of analysis.

\section{DISCUSSION}

To simplify the presentation, I have not discussed some differences in home range size and rates of capture that are related to sex and age. Such differences were found but they had relatively little effect on estimating $D$ for the inner squares and they were not responsible for the great variation in $\hat{r}$ observed in Guam. Other sources of possible bias may have been associated with the state of the population but, with my limited samples, I can only note occassional results that were probably deviant and treat them subjectively. In general, the $S M$ method as employed was very effective in meeting research goals.

My analysis was simplified greatly by working in simple biotopes on a tropical island where the few species present all had relatively similar patterns of trap response. Judging by personal experience in North America, the Philippines and Malaya and by publications of many other workers, this situation may have been exceptional. While I am satisfied that my field methods are sound and of more general applicability, they must be tested in any new situation. The method of analysis is more important than the results.

One cannot simultaneously optimize field methods for a set of species with very diverse patterns of movement and trap response and one must often reach some compromise when heterogeniety and research goals are in conflict. The consequences of the decision should be understood and accepted realistically. Where heterogeniety in trap response is substantial, one may modify standard methods by reducing trap spacing, stratifying traps (Barbehen $n, 1973$ ) extending the trapping period, or by any other means that can be demonstrated to reduce the error of the estimate. The resulting precision may not be high for single observations but we generally search for patterns of change and their causal relationships.

For the dynamic world of small mammals, an estimate of $N$ that lies 
between $T$ and $1.3 T$ meets most needs and one should hesitate to invest much additional effort to improve on that level of precision. For instance, $\mathrm{S} \mathrm{m} \mathrm{it} \mathrm{h} \mathrm{et} \mathrm{al.} \mathrm{(1971)} \mathrm{observed} \mathrm{a} \mathrm{lag} \mathrm{in} \mathrm{catch} \mathrm{for} \mathrm{both} \mathrm{Blarina} \mathrm{and} \mathrm{Ochro-}$ tomys on assessment lines and it seems most unlikely that their great effort was rewarded by an estimate more accurate than could have been achieved by other modifications. Considering the anticipated variation in density over space and time, the extra effort might have been spent better in obtaining a replicate. This, however, is a post hoc conclusion and experimental innovations that are soundly conceived are always welcome after adequate analysis.

Finally, it must be reemphasized that basic methods and their standard modifications are designed for modal situations. When community organization collapses for whatever reason, the best that might be expected from a standard method is that the aberrant situation be recognized. Failure to provide reliable estimates under such circumstances is no fault of the method. In general, what is required is that the method be sensitive to behavioral changes that may be associated with factors such as season, density, and the presence of other species. Confidence in the method comes only from experimental experience and an understanding derived from appropriate analyses.

Acknowledgement: The above research was supported by the National Science Foundation (G-22230), the Smithsonian Institution, and the U. S. Public Health Service (PHS 5 P 10 ES 00139). I thank J. B. Calhoun for endless inspiration, M. Corf, A. P. Covich and O. J. Sext on for helpful discussion and criticism, and $E$. L. S pitznagel, Jr, for statistical counseling.

\section{REFERENCES}

1. A u l a k W., 1967; Estimation of small mammal density in three forest biotopes. Ekol. pol. A., 15: 755-778.

2. Babinska J. \& Bock E., 1969: The effect of prebaiting on captures of rodents. Acta theriol., 14: 267-270.

3. Barbehenn K. R., 1969: Responses of rodents and shrews to patterns of removal trapping. [In: indian Rodent Symposiuma, December 8-11, 1966, D. W. Parrack, convener] Calcutta, India: 247-252.

4. Barbehenn K. R., 1973: The use of stratified traps in estimating density: Peromyscus and Blarina. Acta theriol. 18: 395-402.

5. Barbehenn K. R., 1974: A home range model for Microtus: implications for estimating density and crowding. Amer. Midl. Natur. (in press).

6. Brant D. H., 1962: Measures of the movements and population densities of small rodents. Univ. Calif. Publ. Zool, 62: 105-184.

7. B u chalczyk T. \& P u ck Z, 1968: Estimation of the numbers of Microtus oeconomus using the Standard Minimum method. Acta theriol., 13: 461-482.

8. Cal h ou n J. B., 1964: The social use of space. [In: «Physiological Mammalogy Eds.: Mayer W., \& Van Gelder R.] Academic Press, 1: 1-187, New York.

9. Ca $1 \mathrm{~h}$ ou n J. B. \& Cas by J. U., 1958: Calculation of home range and density of small mammals. U. S. Public Health Monog., 55: 1-24. 
10. Chelkowska H. \& Ryszkowski L., 1967: Causes of higher abundance of small rodents at the edge of sampling areas in forest ecosystems. Ekol. pol. A., 15: 737-747.

11. Faust B. F, Smith M. H. \& Wray W. B., 1971: Distances moved by small mammals as an apparent function of grid size. Acta theriol., 16: 161-177.

12. Gentry J. B., Golley F. B. \& S mith M. H., 1971: Yearly fluctuations in small mammal populations in a southeastern United States hardwood forest. Acta theriol., 16:179-190.

13. Gentry J. B., Smith M. H. \& Beyers R. J., 1971: Use of radioactively tagged bait to study movement patterns in small mammal populations. Ann. zool. Fennici, 8: 17-21.

14. Grodzinski W., Pucek Z. \& R y z kowski L., 1966: Estimation of rodent numbers by means of prebaiting and intensive removal. Acta theriol, 11: $297-314$.

15. H a ns on L., 1969: Home range, population structure and density estimates at removal catches with edge effect. Acta theriol., 14: 153-160.

16. Ha r ris on J. L., 1958 Range of movement of some Malayan rats. J, Mammal., 39: $190-206$.

17. Hay n e D. W., 1949a: Two methods for estimating population from trapping records. J. Mammal., 30: 399-411.

18. H a y $n$ e D. W., 1949b: Calculation of size of home range. J. Mammal, 30: 1-18.

19. Janion S. M., Ryszkowski L. \& Wierzbowska T., 1968: Estimates of number of rodents with variable probability of capture. Acta theriol, 13: $285-294$.

20. Ka ufman D. W., Smith G. O., Jones R. M., Gentry J. B. \& Smith M. H., 1971: Use of assessment lines to estimate density of small mammals. Acta theriol., 16: 127-147.

21. Pearson O. P., 1960: Habits of harvest mice revealed by automatic photographic recorders. J. Mammal, 41: 58-74.

22. Pelik a $\mathrm{n}$ J., 1969: Testing and elimination of the edge effect in trapping small mammals. [In: wEnergy flow through small mammal populations a, Eds: Petrusewicz K, \& Ryszkowski L.J. Polish Sci. Publ.: 57-61. Warszawa.

23. Pelikan J., $\mathrm{Z}$ ejda J. \& $\mathrm{Holisova} \mathrm{V.,} \mathrm{1972:} \mathrm{Influence} \mathrm{of} \mathrm{prebaiting} \mathrm{on}$ the catch of small mammals. Zool. Listy, 21: 209-225.

24. Pucek Z. \& Olszewski J., 1971: Results of extended removal catches of rodents. Ann. zool, Fennici, 8: 37-44.

25. Ryszkowski L., Andrzejewski R. \& Petrusewicz K., 1966: Comparison of estimates of numbers obtained by the methods of release of marked individuals and complete removal of rodents. Aeta theriol. 11: 329-421.

26. S choener T. W., 1971: Theory of feeding strategies. Ann. Rev. Ecol. Syst. 2; $369-404$.

27. S h e p p e W., 1967: The effect of livetrapping on the movements of Peromyscus. Amer. Midl. Nat. $78: 471-480$.

28. Smith M. H., Gentry J. B. \& Golley F. B., 1969: A preliminary report on the examination of small mammal census methods. [In: Energy flow trough small mammal populations *, Eds.: Petrusewicz K., \& Ryszkowski L.]. Polish Sci. Publ.: 25-29. Warszawa.

29. Smith M. H., Blessing R., Chelton J. G., Gentry J. B., Golley F. B. \& McGinnis J. T., 1971: Determining density for small mammal populations using a grid and assessment lines. Acta theriol., 16: 105-125. 
30. Ta naka R., 1966: Simulated removal trapping considered in connection with actual census data in small mammals. Res. popul. Ecol., 8: 14-19.

31. T a naka R., 1972: Investigation into the edge effect by use of capture-recapture data in a vole population. Res. popul. Ecol, 13: 127-151.

22. $\mathrm{Z}$ i p pin $\mathrm{C}$., 1956: An evaluation of the removal method of estimating animal populations. Biometrics, 12: 163-189.

33. Zippin C., 1958: The removal method of population estimation. J. Wildl. Manage. 22: 82-90.

Accepted, Febr. 15, 1974.

Center for the Biology of Natural Systems, Washington University, St. Louis, Missouri 63130 , USA
Present address:

WH 568

U.S. Environmental Protection Agency, Washington, D.C. 70460, USA,

\section{Kyle R. BARBEHENN}

OZNACZANIE ZAGESZCZENIA I AREAEU OSOBNICZEGO DROGA ODEOWOW, NA PRZYKEADZIE GRYZONI I RYJOWEK WYSPY GUAM

\section{Streszczenie}

Zakładając określone zależnosci pomiędzy promieniem $(r)$ arealu osobniczego, prawdopodobieństwem (p) łowienia i polożeniem srodka arealu osobnfczego względem badanej powierzehni opracowano model, który pozwala przewidzieć żarówno względna lownosć na każdej powierzchni odlownej jak i oczekiwane tempo wylowu. Model ten został sprawdzony przy odlowach Suncus murinus oraz Rattus rattus i $R$. exulans prowadzonych na wyspie Guam. Na zmienne eksperymentalne składało się zróżnicowanie rozmieszczenia pułapek poprzez pozostawienie ich na tym samym miejscu lub przesunięcie do punktów środkowych po dwudniowym wyłowie albo też przedłużenie odłowów.

Na poziomie populacyjnym $r$ wahalo sie od $7-30 \mathrm{~m}$ dla Suncus i $R$. rattus oraz of $4-20 \mathrm{~m}$ w przypadku $R$. exulans. Zaobserwowane wzorce odłowr sa zgodne z teza Calhoun'a, w myśl której populacje o stosunkowo małych arealach powiększają swe areały $w$ wyniku wylowu. Zarówno $z$ przeslanek teoretycznych jak i empirycznych wynika, że dane $z$ odłowu na obrzeżach powierzchni nie mogą słuzyć do wiarygodnej oceny gęstosci populacji. Przedział ufnosci dla $\hat{N}$ wyprowadzono z SE Zippin'a $(\hat{p})$ dla indywidualnych prób, ale zgodnosce $\hat{p}$ w próbach pozwala na bardziej precyzyjną ocenę $\bar{p} i$ wyraża zmniejszenie przedziału ufnosci dla małych prób. Niektóre odchylenia wyników sq nieuniknione i mogą być traktowane subiektywnie, nie dyskredytując metody kwadratow wewnetrznych $w$ sytuacjach, w których jest ona ogólnie odpowiednia. Jednakże poprawność metody należy testowat w każdej konkretnej sytuacji. 